Heverton Zambrini

Estudo de dados clínicos e laboratoriais de pacientes com aids e lipodistrofia atendidos no Programa de Lipodistrofia do Hospital Heliópolis

Dissertação apresentada à Faculdade de Medicina da Universidade de São Paulo para obtenção do título de Mestre em Ciências

Programa de Doenças Infecciosas e Parasitárias

Orientador: Prof. Dr. Antonio Carlos Nicodemo 
Dados Internacionais de Catalogação na Publicação (CIP)

Preparada pela Biblioteca da

Faculdade de Medicina da Universidade de São Paulo

Creprodução autorizada pelo autor

\section{Zambrini, Heverton}

Estudo de dados clínicos e laboratoriais de pacientes com aids e lipodistrofia atendidos no Programa de Lipodistrofia do Hospital Heliópolis / Heverton Zambrini. -- São Paulo, 2011.

Dissertação(mestrado)--Faculdade de Medicina da Universidade de São Paulo. Programa de Doenças Infecciosas e Parasitárias.

Orientador: Antonio Carlos Nicodemo.

Descritores: 1.Síndrome de lipodistrofia associada ao HIV 2.AIDS 3.HIV 4.Síndrome metabólica 5.Antropometria

USP/FM/DBD-276/11 
Dedico esta tese a todos os pacientes que no dia-a-dia me ensinaram o real valor da lipodistrofia em suas vidas. 


\section{Agradecimentos}

- Agradeço ao Prof. Dr. Antonio Carlos Nicodemo que acompanhou o desenvolvimento desta pesquisa.

- Agradeço também aos componentes da banca de qualificação, Profa . Dra

Eliana Bataglia Gutierrez, Prof. Dr. Ricardo Tapajós e Prof. Dr Eder Carlos Rocha Quintão, pelas sugestões, criticas e palavras de incentivo.

- Agradeço aos colegas do Hospital Heliópolis que colaboram com o Programa de Lipodistrofia, ponto de partida para este estudo. 
Esta dissertação esta de acordo com as seguintes normas, em vigor no momento desta publicação:

Referências: adaptado de International Committee of Medical Journal Editors (Vancouver)

Universidade de São Paulo. Faculdade de Medicina. Divisão de Biblioteca e Documentação. Guia de apresentação de dissertações, teses e monografias. Elaborado por Anneliese Carneiro da Cunha, Maria Julia de A. L. Freddi, Maria Fazanelli Crestana, Marinalva de Souza Aragão, Suely Campos Cardoso, Valéria Vilhena. 3a ed. São Paulo : Divisão de Biblioteca e Documentação; 2011

Abreviaturas dos títulos dos periódicos de acordo com List of Journals Indexed in Index Medicun 


\section{Sumário}

Lista de abreviaturas e símbolos

Lista de figuras

Lista de gráficos

Lista de tabelas

Lista de quadros

Resumo

Summary

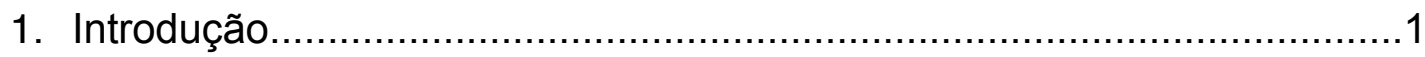

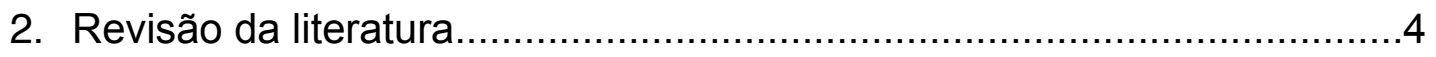

2.1.Definição..............................................................................

2.2.Prevalência....................................................................... 11

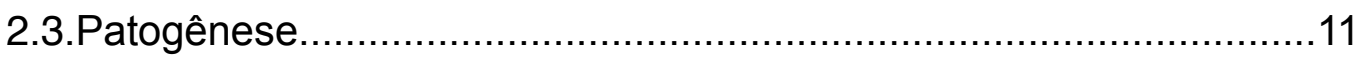

2.4.Alterações metabólicas associadas à lipodistrofia..........................17

2.5.Diagnóstico...................................................................... 19

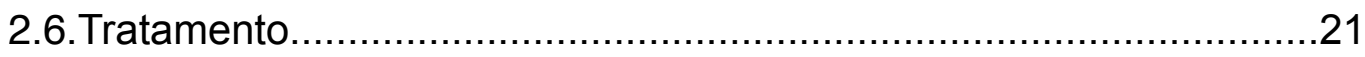

3. Justificativa para a realização do projeto........................................23

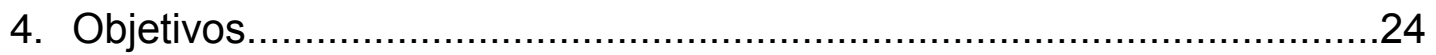

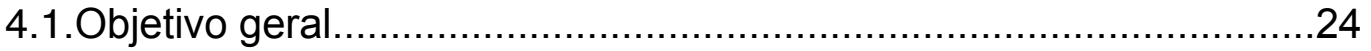

4.2. Objetivos específicos......................................................24

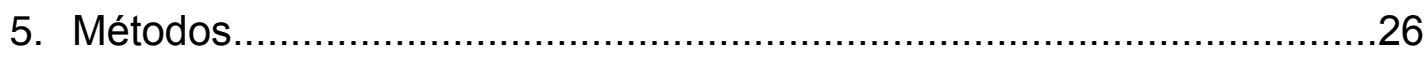

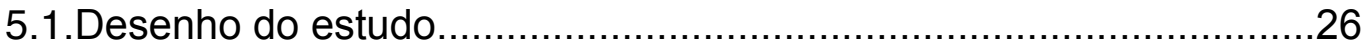

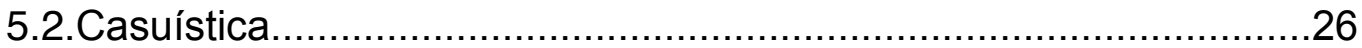


5.3.Critérios de inclusão.

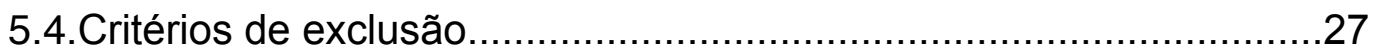

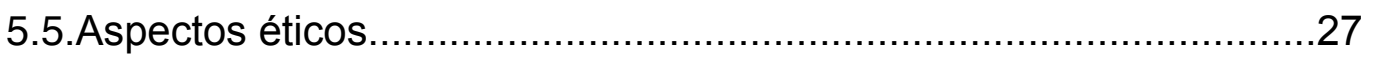

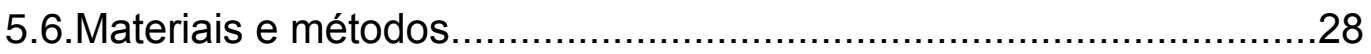

5.6.1.Avaliação antropométrica...............................................28

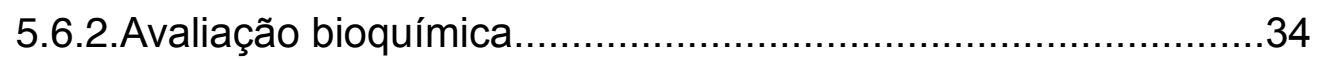

5.6.3.Análise dos esquemas antirretrovirais.............................34

5.6.4.Classificação da lipodistrofia...........................................35

5.6.5.Classificação da síndrome metabólica..................................36

5.6.6. Classificação do nível de atividade física............................36

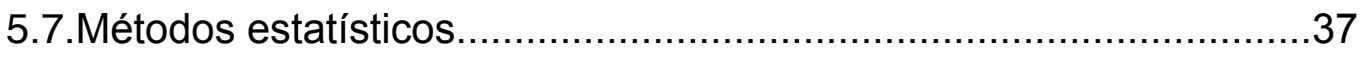

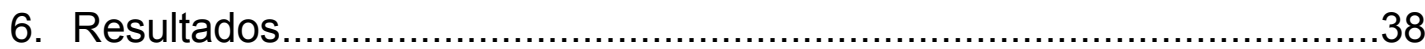

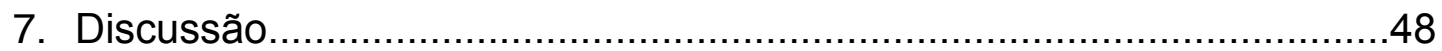

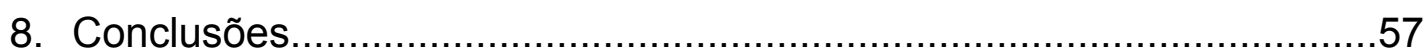

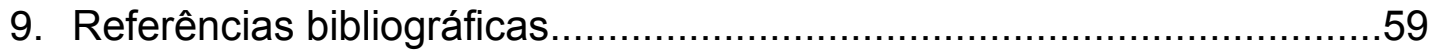

Apêndice 


\section{Lista de abreviaturas e símbolos}

AACE - American Association of clinical Endocrinologists

ABC - Abacavir

aids - Síndrome da Imunodeficiência Adquirida

AMP - Amprenavir

ARV - Antirretroviral

ATP III - III Adult Treatment Panel

AZT - Zidovudina

CB - Circunferência do braço

CC - Circunferência da cintura

CMB - Circunferência muscular do braço

CQ - Circunferência do quadril

CRABP-1 - Cellular retinoic acid-binding protein 1

CT - Colesterol total

d4T - Estavudina

DCB - Dobra cutânea do bíceps

DCS - Dobra cutânea subescapular

DCSI - Dobra cutânea supra-ilíaca

DCT - Dobra cutânea do tríceps

DCV - Doença cardiovascular

DEXA - Dual energy X-ray absorptiometry

DM - Diabetes Mellitus

DNA - Ácido desoxirribonucléico

DRV - Darunavir 
ETV - Etravirine

FKHR - Fator de transcrição da insulina - Forkhead transcription factor FPV - Fosamprenavir

HAART - Highly Active AntiRetroviral Treatment

HDL - Lipoproteína de alta densidade

HIV - Vírus da imunodeficiência humana

IDV - Indinavir

IF - Inibidor de fusão

II - Inibidor da integrase

IMC - Índice de massa corpórea

IP - Inibidor da protease

ITRN - Inibidor da transcriptase reversa análogo de nucleosídeo

ITRNN - Inibidor da transcriptase reversa não análogo de nucleosídeo

LDL - Lipoproteína de baixa densidade

mtDNA - DNA mitocondrial

NCEP - National Cholesterol Education Program

NFV - Nelfinavir

NVP - Nevirapina

OMS - Organização Mundial de Saúde

PPARY - Peroxisome proliferator-activated receptor gamma

RAL - Raltegravir

$R C Q$ - Relação cintura-quadril

RI - Resistência insulínica

RNM - Ressonância nuclear magnética 
ROS - Espécies oxigenio-reativas

RTV - Ritonavir

SLS - Síndrome da Lipodistrofia

SM - Síndrome metabólica

SQV - Saquinavir

T20 - Enfuvirtide

TARV - Terapia antirretroviral

TAS - Tecido adipose subcutâneo

Tat - Trans-Activator of trascription

TAV - Tecido adiposo visceral

TC - Tomografia computadorizada

TDF - Tenofovir

TG - Triglicérides

TM - Toxicidade mitocondrial

UNAIDS - United Nations Programme on HIVIAids

Vpr - Viral protein $\mathrm{R}$

USG - Ultrassonografia 


\section{Lista de figuras}

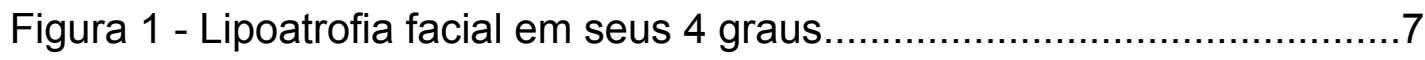

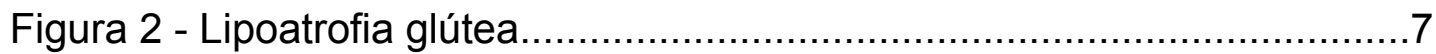

Figura 3 - Apresentação clínica da lipohipertrofia: dorso-cervical, mamas/ abdome e forma mista..................................................

Figura 4 - Etapas da diferenciação e maturação da célula adiposa..............13

Figura 5 - Mecanismos envolvidos na patogênese da lipodistrofia associada ao HIV

Figura 6 - Distribuição da população estudada atendida no Programa de Lipodistrofia do Hospital Heliópolis-SP por Direção Regional de Saúde (DRS) no Estado de São Paulo no período de 01

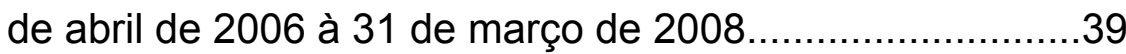




\section{Lista de gráficos}

Gráfico 1 - Distribuição dos esquemas ARVs de acordo com as associações mais prevalentes em indivíduos atendidos no programa de lipodistrofia do Hospital Heliópolis-SP para correções cirúrgicas, abril de 2006 a março de 2008

Gráfico 2 - Padrão fenotípico dos indivíduos HIV/Aids e lipodistrofia atendidos no programa de lipodistrofia do Hospital Heliópolis-SP para correções cirúrgicas, abril de 2006 a março de 2008.

Gráfico 3 - Distribuição da lipoatrofia de acordo com a região anatômica e sexo em indivíduos atendidos no programa de lipodistrofia do Hospital Heliópolis-SP para correções cirúrgicas, abril de 2006 a março de 2008.

Gráfico 4 - Distribuição da lipohipertrofia de acordo com a região anatômica e sexo em indivíduos atendidos no programa de lipodistrofia do Hospital Heliópolis-SP para correções cirúrgicas, abril de 2006 a março de 2008. 


\section{Lista de tabelas}

Tabela 1 - Distribuição da população estudada de acordo com as características demográficas, tempo de diagnóstico do HIV, tabagismo, atividade física e síndrome metabólica, abril de 2006 a março de 2008.

Tabela 2 - Distribuição da população estudada de acordo com os dados laboratoriais (CD4, carga viral, colesterol total, HDL colesterol, LDL colesterol, triglicérides e glicemia) de abril de 2006 a março de 2008.

Tabela 3 - Avaliação antropométrica dos indivíduos estudados de acordo com os indicadores da distribuição de gordura corporal e indicadores de aumento de risco cardiovascular, abril 2006 a março de 2008.

Tabela 4 - Associação entre síndrome metabólica e os fenótipos da lipodistrofia em indivíduos portadores de lipodistrofia/HIV atendidos no programa de lipodistrofia do Hospital Heliópolis no período de abril de 2006 à março de 2008 47

Tabela 5 - Associação de lipodistrofia e indicadores antropométricos com forte relação com o aumento de risco cardiovascular em pacientes HIV/Aids atendidos no programa de lipodistrofia do Hospital Heliópolis-SP para correções cirúrgicas da lipodistrofia de abril 2006 a março de 2008 48 


\section{Lista de Quadros}

Quadro 1 - Classificação do estado nutricional de indivíduos com menos de 60 anos, de acordo com o IMC 30

Quadro 2 - Classificação de estado nutricional de indivíduos com mais de 60 anos, de acordo com o IMC

Quadro 3 - Classificação do estado nutricional de acordo com os percentis da circunferência do braço 33

Quadro 4 - Classificação do estado nutricional de acordo com os percentis da circunferência muscular do braço. 34

Quadro 5 - Critérios da síndrome metabólica segundo o National Cholesterol Education Program (NCEP) - ATP III. 


\section{RESUMO}

Zambrini $\mathrm{H}$. Estudo de dados clínicos e laboratoriais de pacientes com aids e lipodistrofia atendidos no Programa de Lipodistrofia do Hospital Heliópolis [dissertação]. São Paulo: Faculdade de Medicina, Universidade de São Paulo; 2011.

INTRODUÇÃO: O termo "lipodistrofia associada ao HIV" foi introduzido aproximadamente dois anos após o início do uso dos inibidores da protease e, desde então, várias definições têm sido utilizadas para descrever a extensão das complicações morfológicas e metabólicas associadas à infecção pelo HIV e à terapia antirretroviral. Inúmeros estudos clínicos têm sido desenvolvidos nos últimos 10 anos com o objetivo de melhor definir as alterações corporais associadas à infecção pelo HIV e identificar os fatores de riscos dependentes ou independentes a essas alterações. MÉTODO: Neste estudo transversal retrospectivo realizado entre 01 de abril de 2006 e 31 de março de 2008 foram levantados os dados de 341 pacientes com HIV/ AIDS e lipodistrofia encaminhados para realização de procedimentos corretivos cirúrgicos no Hospital Heliópolis-SP. Os principais dados coletados foram: perfil fenotípico da lipodistrofia, dados laboratoriais relativos aos valores de colesterol, HDL-colesterol, LDL-colesterol, triglicérides, glicemia, contagem de células CD4, carga viral do HIV e medidas antropométricas. Foi realizada a análise da associação da síndrome metabólica com a lipodistrofia e a associação dos dados antropométricos indicativos de maior risco cardiovascular com a lipodistrofia. RESULTADOS: do total de pacientes, 198 (58,1\%) eram do sexo feminino e $143(41,9 \%)$ do sexo masculino, com predomínio de idade na faixa dos 40-49 anos. A mediana do tempo de diagnóstico da infecção pelo HIV foi de 10 anos e em $55,7 \%$ dos pacientes o tempo de terapia antirretroviral foi superior a 24 meses. Na avaliação dos dados laboratoriais, 44,3\% dos pacientes apresentaram elevação dos níveis de colesterol (>200mg/dl), 55,7\% redução do HDL-colesterol (<40mg/dl e $<50 \mathrm{mg} / \mathrm{dl}$ respectivamente para sexo 
masculino e feminino), 34,3\% elevação do LDL-c, 63,6\% elevação dos triglicérides e 31,7\% elevação da glicemia. A síndrome metabólica esteve presente em 40,2\% de acordo com os critérios do NCEP-ATPIII. Os dados antropométricos utilizados para avaliar grau de nutrição ( índice de massa corporal, circunferência muscular do braço e circunferência do braço) mostraram desnutrição em 6,5\%, 7,4\% e 16,4\% respectivamente; eutrofia em $56 \%, 67,6 \%$ e $75,4 \%$ respectivamente ; excesso de peso/obesidade em $37,5 \%, 25 \%$ e $8,2 \%$ respectivamente. A porcentagem de gordura corporal calculada utilizando as dobras cutâneas demonstrou um excesso de gordura corporal em $85,9 \%$ dos pacientes. As variáveis antropométricas que sugerem risco para doença cardiovascular (circunferência da cintura e relação cintura-quadril) estavam elevadas em $61,3 \%$ e $89,4 \%$ respectivamente. O padrão fenotípico da lipodistrofia encontrado foi: $57,8 \%$ forma mista, 21,7\% lipoatrofia e 20,5\% lipohipertrofia. Na estratificação por gênero e fenótipos, a lipoatrofia facial foi mais prevalente no sexo masculino $(62,2 \%)$ e a lipoatrofia glútea no sexo feminino $(74,3 \%)$ enquanto que a lipohipertrofia abdominal foi mais prevalente em ambos os sexos $(40,5 \%$ sexo feminino e $12,5 \%$ sexo masculino). CONCLUSÕES: O estudo mostra uma relação da lipodistrofia com os indicadores antropométricos com forte associação ao aumento de risco cardiovascular. Houve uma associação elevada da lipodistrofia com síndrome metabólica. A análise do perfil metabólico se mostrou desfavorável nesta população estudada corroborando para o aumento de risco para doenças cardiovasculares. As características clínicas gerais dos pacientes neste estudo podem demonstrar um estágio mais avançado da lipodistrofia com as alterações metabólicas mais significativas.

Descritores: Síndrome de lipodistrofia associada ao HIV; AIDS; HIV; Síndrome metabólica; Antropometria 


\section{SUMMARY}

Zambrini H. Study of clinical and laboratory data of patients with AIDS and lipodystrophy met in Lipodystrophy Program of Heliopolis Hospital [dissertation]. São Paulo: School of Medicine, University of São Paulo.

INTRODUCTION: The term "HIV-associated lipodystrophy" has been introduced about two years after the start of the use of protease inhibitors and, since then, various definitions have been used to describe the extent of morphological complications and metabolic diseases associated with HIV infection and antiretroviral therapy. Numerous clinical studies have been developed in the last 10 years with the goal of better define the body changes associated with HIV infection and identify dependent or independent risk factors. METHOD: In this retrospective cross-sectional study conducted between 1 April 2006 and 31 March 2008 were collected data from 341 patients with HIV / AIDS and Lipodystrophy referred to perform corrective surgical procedures at Hospital Heliopolis, São Paulo. The main data collected were: phenotypic profile of lipodystrophy, data laboratory values for cholesterol, HDL- cholesterol, LDL-cholesterol, triglycerides, blood sugar, count CD4 cell count, HIV viral load and anthropometric measures. Associations analysis were performed between the metabolic syndrome and lipodystrophy and between the anthropometric data indicative of increased cardiovascular risk with lipodystrophy. RESULTS: of the total patients, 198 (58.1\%) were female and $143(41.9 \%)$ were male, with a predominance of old in the range of 40-49 years. The median time of diagnosis of HIV infection was 10 years and $55.7 \%$ of the patients had the time of antiretroviral therapy longer than 24 months. In evaluating laboratory data, $44.3 \%$ of patients has elevated levels of cholesterol (> 200mg/dl), 55.7\% reduction HDL-cholesterol (<40mg/dl and <50 mg / dl respectively for sex male and female), 34.3\% increase in LDL-C, $63.6 \%$ increase $31.7 \%$ triglycerides and high glucose level. Metabolic syndrome was present in $40.2 \%$ according to the criteria of NCEP-ATPIII. The anthropometric data used to evaluate level of nutrition 
(body mass index, circumference arm muscle and arm circumference) showed malnutrition at $6.5 \%, 7.4 \%$ and $16.4 \%$ respectively, eutrophic status in $56 \%, 67.6 \%$ and $75.4 \%$ respectively, overweight / obesity status in $37.5 \%$, $25 \%$ and $8.2 \%$ respectively. The percentage of fat calculated using the body skinfolds showed a excess body fat in $85.9 \%$ of patients. Variables suggest that anthropometric risk for cardiovascular disease (waist circumference and waist-hip ratio) were elevated in $61.3 \%$ and $89.4 \%$ respectively. The pattern of phenotypic lipodystrophy was found: $57.8 \%$ of mixed form, $21.7 \%$ of lipoatrophy and $20.5 \%$ of lipohypertrophy. When stratifying by gender and phenotypes, the facial lipoatrophy was more prevalent in male $(62.2 \%)$ and buttock lipoatrophy in females $(74.3 \%)$ while the abdominal lipohypertrophy was more prevalent in both sexes (40.5\% female and $12.5 \%$ male). CONCLUSIONS: The study shows a relationship between lipodystrophy and anthropometric indicators with increased cardiovascular risk. There was an association of high lipodystrophy and metabolic syndrome. Profile metabolic analysis proved negative in the population studied corroborating to the increased risk for cardiovascular disease. The general clinical characteristics of patients in this study may demonstrate a advanced stage of lipodystrophy with more significant metabolic abnormalities.

Descriptors: HIV-Associated Lipodystrophy Syndrome; AIDS; HIV; Metabolic Syndrome; Anthropometry 


\section{Introdução:}

A história da epidemia causada pelo vírus da imunodeficiência humana (HIV) está associada, em seus momentos iniciais, à grande comoção pública decorrente do desconhecimento dos seus agentes, mortalidade e, principalmente, pela especificidade do grupo social ao qual parecia estar associada (homossexuais masculinos). Neste período (décadas de 1980 e 1990) houve um aumento exponencial da mortalidade decorrente dessa epidemia, com restritas opções terapêuticas centradas no tratamento e controle das infecções oportunistas ${ }^{(1)}$.

Os dados publicados em novembro de 2010 pela The Joint United Nations Programme on HIVIAIDS (UNAIDS) mostram uma estimativa global para a epidemia, no final de 2009 de cerca de 33,3 milhões de pessoas (31,4 - 35,3 milhões) vivendo com HIVIAIDS, 2,6 milhões de novas infecções e 1,8 milhões de mortes devido ao HIVIAIDS. Neste mesmo período acredita-se que existam 1,4 milhões de adultos e crianças vivendo com HIV/ AIDS, 92.000 novos infectados (adultos e crianças) e 58.000 óbitos em adultos e crianças na América Central e Latina(2). No Brasil, de 1980 até junho/2010, foram notificados 592.914 casos de AIDS dos quais $58 \%$ localizados na região sudeste. Em 2009, no Brasil, foram notificados 38.538 novos casos de AIDS. Há dados que mostram uma queda de $20 \%$ no número de novas infecções pelo HIV no mundo nos últimos 10 anos.(3)

As opções de tratamento até 1996 limitavam-se à escolha de dois inibidores da transcriptase reversa análogos dos nucleosídeos (ITRNs) 
associada ao controle dos sintomas. Desta forma conseguia-se retardar a progressão da doença e melhorar a qualidade de vida dos pacientes. Porém, a conseqüência inevitável do fracasso em deter a replicação viral era o desenvolvimento progressivo da imunodeficiência e morte. A partir de 1996, com a introdução de nova classe de antirretrovirais (ARV), os inibidores de protease (IP), os pacientes passaram a receber uma terapia mais potente $\mathrm{e}$ eficaz, denominada de Highly Active AntiRetroviral Treatment (HAART). A introdução de novas drogas e a adoção de guias de orientações de tratamento (guidelines) levou a um declínio acentuado da morbidade e mortalidade associada ao HIV e a melhorias significativas na qualidade de vida. ${ }^{(4)}$.

Concomitantemente à introdução dos IPs em 1996, foi observado o aparecimento de alterações na distribuição da gordura corporal nos pacientes em uso de antirretrovirais. Esta situação foi denominada de Síndrome da Lipodistrofia $(S L){ }^{(5,6,7,8)}$.

O primeiro relato de redistribuição de gordura corpórea em um paciente infectado pelo HIV em uso de TARV foi publicado em $1997^{(8)}$. Inicialmente foi denominada de "Crixbelly"(9), pois os primeiros casos de redistribuição de gordura corporal foram observados após a utilização do Crixivan $®$ (indinavir). Com o surgimento de novos IPs, concluiu-se que a redistribuição da gordura corporal não era um efeito exclusivo do indinavir, sendo esta denominação abandonada. Miller e cols.(7) observaram semelhanças clínicas entre pacientes com Síndrome de Cushing e a redistribuição de gordura corporal nos pacientes HIV em uso de TARV e 
passaram a denominá-la de Pseudo Síndrome de Cushing. Estudos posteriores não conseguiram demonstrar alterações no eixo hipotálamohipófise-adrenal dos pacientes HIV, sendo assim abandonada essa nomenclatura.

Atualmente, algumas sinonímias são empregadas, tais como Síndrome de Redistribuição da Gordura Corporal, Síndrome da Lipodistrofia, Lipodistrofia Dislipidêmica ou simplesmente Lipodistrofia.

A associação das alterações da redistribuição de gordura pode acontecer em conjunto com alterações metabólicas, sendo este padrão semelhante ao observado na "síndrome metabólica". (10)

A lipodistrofia tem um impacto importante na qualidade de vida destes pacientes causando-Ihes problemas físicos, psicológicos e sociais. Alterações físicas são traduzidas por sintomas como distensão abdominal, refluxo gastroesofágico, dificuldade para realizar exercícios e dormir e lombalgia, devido à ginecomastia (11). As alterações psicossociais estão relacionadas a sentimentos negativos frente às alterações corpóreas, tais como baixa auto-estima, isolamento social e depressão ${ }^{(12,13)}$.

A adesão tende a diminuir ao longo do tempo, após o diagnóstico de lipodistrofia, trazendo como conseqüências o desenvolvimento de resistência aos antirretrovirais e o aumento da morbi-mortalidade relacionada à infecção pelo HIV (14).

Os efeitos tardios da lipodistrofia associadas ao HIV, incluindo os distúrbios metabólicos típicos da homeostase da glicose e dos lípides, ainda não foram completamente elucidados. 


\section{Revisão da literatura}

\subsection{Definição}

As lipodistrofias pertencem à um grupo heterogêneo de desordens do tecido adiposo caracterizadas pela alteração seletiva de gordura de várias partes do corpo. A extensão destas desordens se relaciona com a gravidade das complicações metabólicas: pacientes com lipodistrofias localizadas apresentam apenas problemas estéticos, enquanto aqueles com lipodistrofias generalizadas podem apresentar resistência grave à insulina, hipertrigliceridemia, diabetes mellitus, esteatose hepática e envelhecimento precoce $^{(15)}$.

As lipodistrofias podem ser classificadas em dois tipos principais:

\section{familiares e adquiridas. (15)}

Os principais subtipos de lipodistrofias familiares são:

- lipodistrofia generalizada congênita - uma doença de herança autossômico-recessiva caracterizada pela ausência quase completa de tecido adiposo metabolicamente ativo desde o nascimento

- lipodistrofia familiar parcial, tipo Dunnigan - uma doença autossômica dominante caracterizada pela perda de gordura subcutânea a partir das extremidades na puberdade e acúmulo de gordura na face e região cervical. 
As lipodistrofias adquiridas são divididas em:

- lipodistrofia generalizada adquirida,

- lipodistrofia parcial adquirida,

- lipodistrofia em pacientes HIV,

- lipodistrofia localizada secundária (drogas, pressão, trauma, paniculitis),

- lipodistrofia semicircularis,

- lipodistrofia abdominal centrifuga e idiopática.

O termo "lipodistrofia associada ao HIV" foi introduzido aproximadamente dois anos após o início do uso dos inibidores da protease (IP) e, desde então, várias definições têm sido utilizadas para descrever a extensão das complicações morfológicas e metabólicas associadas à infecção pelo HIV e à TARV $(5,16,17)$.

As alterações corporais compreendem:

- lipoatrofia (redução da gordura em regiões periféricas, como braços, pernas, face e nádegas, podendo apresentar proeminência muscular e venosa relativa) (figura 1 e 2)

- lipohipertrofia ou lipoacumulação (acúmulo de gordura na região abdominal, presença de gibosidade dorsal, "ginecomastia" nos homens e aumento de mamas em mulheres e acúmulo de gordura em diversos locais do corpo como a região submentoniana, pubiana, etc.) (figura 3)

- forma mista (associação de lipoatrofia e lipohipertrofia). (figura 3) 
Figura 1 - Lipoatrofia facial em seus 4 graus

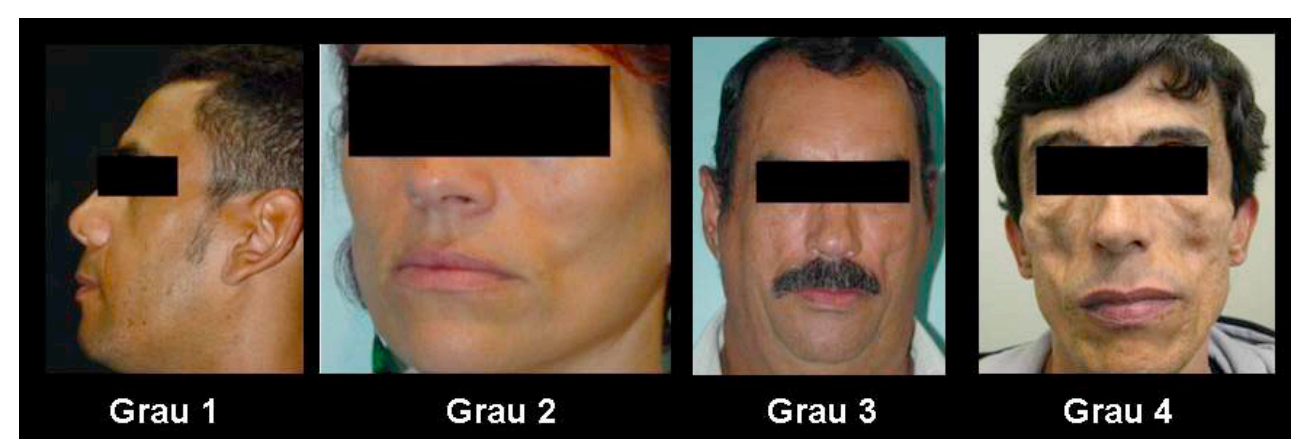

Nota: Pacientes do ambulatório de lipodistrofia do Hospital Heliópolis

Figura 2 - Lipoatrofia glútea

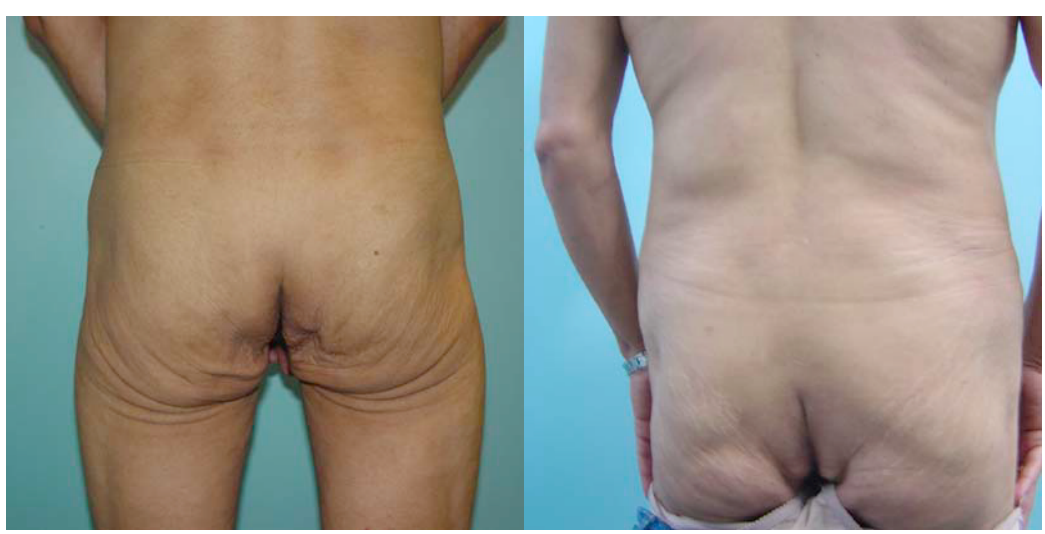

Nota: Pacientes do ambulatório de lipodistrofia do Hospital Heliópolis

Figura 3 - Apresentações clínicas da lipohipertrofia dorso-cervical (giba), mama/abdome e forma mista.

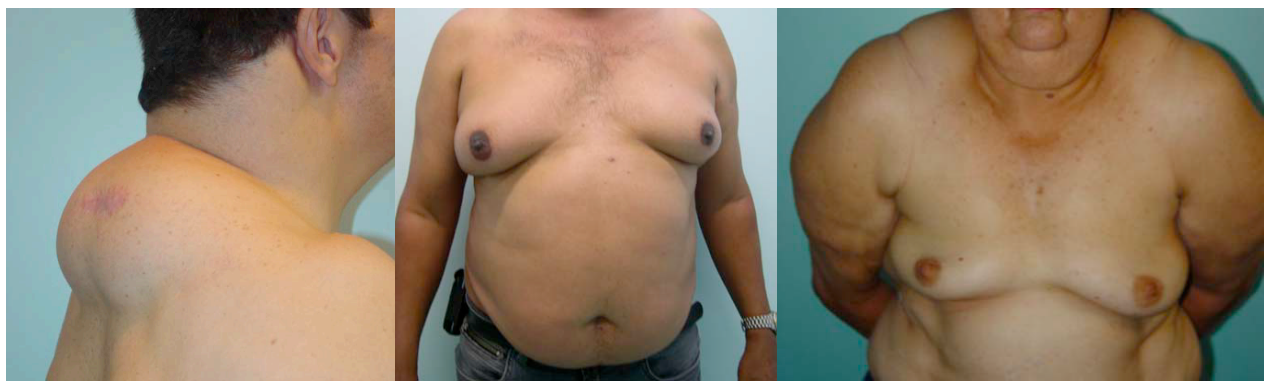

Nota: Pacientes do ambulatório de lipodistrofia do Hospital Heliópolis 
Os distúrbios metabólicos associados são:

- alterações na homeostase da glicose (resistência à insulina e/ou diabetes mellitus)

- alterações lipídicas (hipercolesterolemia, hipertrigliceridemia ou ambas)

- acidose lática (lactato sérico $>5 \mathrm{mmol} / \mathrm{L}$ e $\mathrm{pH}$ sérico $<7,35$ ).

A lipodistrofia é reconhecida primariamente pela perda de gordura do tecido adiposo subcutâneo da face e das regiões periféricas, particularmente das extremidades (membros). Os pacientes atingidos por essa síndrome apresentam proeminência das veias e da musculatura das extremidades. Alguns indivíduos exibem concomitantemente deposição de gordura ao redor do pescoço, sobre a coluna cervical (giba) e na região abdominal (visceral). O aumento da mama tem sido observado nas mulheres e nos homens, entretanto ainda não está esclarecido se este aumento é ocasionado pelo excesso de tecido subcutâneo, hipertrofia glandular ou ambos. Comparado aos homens, a perda de gordura periférica nas mulheres com lipodistrofia é freqüentemente mais sutil, enquanto que o aumento da gordura central é a principal queixa. A mulher também pode desenvolver irregularidades no ciclo menstrual. $(18,19)$

Os sinais físicos da lipodistrofia normalmente aparecem progressivamente, aumentando em gravidade, por um período de 18 a 24 meses e, em seguida, estabilizam durante pelo menos dois anos. Podem acometer homens, mulheres e crianças. Em alguns pacientes, a lipoatrofia precede a lipohipertrofia. ${ }^{(20)}$ Estima-se que para a lipodistrofia ser visível é 
necessária alteração de pelo menos $30 \%$ do tecido adiposo tanto para mais como para menos conforme Podzamczer. (21)

Não existe um consenso na literatura quanto à definição da lipodistrofia em pacientes com HIV, o que dificulta determinar a sua real prevalência, etiologia e tratamento. A maioria dos estudos de lipodistrofia e HIV é baseada em sintomas subjetivos reportados pelos pacientes, em sinais clínicos observados pela equipe de saúde que acompanha o paciente ou na combinação de ambos. Estas observações podem ser confirmadas por medidas antropométricas ou por exames radiológicos.

Enquanto uma parcela dos indivíduos soropositivos para HIV com lipodistrofia apresenta-se clinicamente estável, sem perda significativa de peso ou na distribuição da gordura corporal, com média de contagem de células CD4+ relativamente alta e a carga viral baixa devido a TARV, os pacientes atingidos pela lipodistrofia grave estão freqüentemente preocupados com as deformidades faciais e a aparência do corpo. Com isso, alteram a sua postura, modificam o seu vestuário e sentem desconforto na giba quando em posição supina ${ }^{(20)}$. Além disso, devido às deformidades corporais, muitos indivíduos tendem a interromper o tratamento antirretroviral ( 1314$)$.

Apesar dos relatos iniciais de uma associação entre os IPs e a lipodistrofia, observou-se rapidamente que outros medicamentos também estavam implicados no desenvolvimento desta síndrome (22). Em 1999 foi descrita a associação entre análogos timidínicos, particularmente a estavudina (d4T) (17), e a perda de gordura, e esta associação foi sustentada 
pela melhora da gordura subcutânea e dos níveis de triglicérides após a troca do d4T por zidovudina (AZT), abacavir (ABC) ou tenofovir (TDF) ${ }^{(23,24)}$

Com o decorrer do tempo, ficou claro que os componentes da lipodistrofia são resultantes de processos parcialmente independentes. Antirretrovirais diferentes estão associados a vários tipos e graus de toxicidade e a síndrome da lipodistrofia é o resultado de uma complexa interação entre diversos fatores. Em geral, os análogos timidínicos, especialmente o d4T, estão associados com lipoatrofia e os IP com lipohipertrofia ${ }^{(19,25)}$. A co-infecção com o vírus da hepatite $\mathrm{C}$ aumenta o risco de lipoatrofia em pacientes infectados pelo HIV (26).

A lipodistrofia também tem sido observada em doentes em tratamento durante a infecção primária pelo HIV, assim como em indivíduos não infectados e que tenham recebido tratamento antirretroviral profilático pósexposição de risco. Também se observa alterações da distribuição do tecido gorduroso corporal em pacientes HIV que não estão em uso de TARV. Especula-se, através destes dados, que a lipodistrofia pode aparecer a qualquer momento a partir da infecção pelo HIV.

Ao longo do tempo tem sido observado que os componentes desta síndrome podem ocorrer em conjunto ou isoladamente, dependendo de uma interação complexa entre vários fatores incluindo o hospedeiro, a doença e a TARV com várias vias patogênicas distintas ${ }^{(27)}$.

Inúmeros estudos clínicos têm sido desenvolvidos nos últimos 10 anos com o objetivo de melhor definir as alterações corporais associadas à infecção pelo HIV e identificar os fatores de riscos dependentes ou 
independentes a essas alterações. Resultados epidemiológicos de nove grandes estudos internacionais revelam que a exposição e o tempo de exposição aos ITRNs principalmente ao d4T, idade, contagem de células CD4, carga viral e indivíduos caucasianos são os fatores de risco mais relacionados à lipoatrofia. Já a lipohipertrofia tem como fatores de risco relacionados: a duração da TARV, a contagem de CD4 e a carga viral, a idade e uso de IP. (28)

\subsection{Prevalência}

Devido às diferenças nos critérios diagnósticos, seleção de população de estudo e duração do seguimento, existem diversos relatos de prevalência da lipodistrofia, variando de $8-84 \%$ com uma média de $42 \%$ nos pacientes tratados com regimes com IP ${ }^{(29)}$. A média de incidência varia de 7,3 a 11,7 por 100 pacientes-ano ${ }^{(29)}$. Apesar destas diferenças, uma alta prevalência tem sido descrita em pacientes após um longo tempo de tratamento. Em uma análise de dados agrupados, a prevalência de lipodistrofia foi de $17 \%$ em adultos tratados com IP por menos de um ano e de $43 \%$ naqueles tratados por um ano ou mais. A prevalência da lipodistrofia nas mulheres tem sido observada entre $10,5 \%$ a $37 \%$, mas provavelmente estas porcentagens são subestimadas ${ }^{(29,30)}$. Segundo Jacobson $(2005)^{(30)}$ cada seis meses de tratamento com TARV associa-se a $45 \%$ de aumento de risco de lipodistrofia . Estas alterações não ocorrem necessariamente associadas no mesmo paciente ou com a mesma freqüência. A perda de tecido adiposo ocorre relativamente em uma freqüência maior, enquanto que a lipomatose 
na região dorso cervical é mais incomum ${ }^{(27)}$. Dados brasileiros de Diehl et al (2008) em uma análise com 180 pacientes mostram que 57\% dos entrevistados relataram alguma alteração do contorno corporal após o diagnóstico da infecção pelo HIV (31). Em outro estudo brasileiro 59,3\% de 102 pacientes HIV apresentavam lipodistrofia (32). Santos e col. através de entrevistas com pacientes portadores do HIV em São Paulo reportaram uma taxa de $64,3 \%$ de percepção da modificação da gordura corporal. (33)

\subsection{Patogênese}

O papel do tecido adiposo era considerado apenas como "armazenador de lípides" e fonte de ácidos graxos livres nos estados pósabsortivos para fornecer energia à maioria dos tecidos. Atualmente o tecido adiposo é considerado como parte integrante de vários processos homeostáticos tais como o controle da pressão sangüínea e a sensibilidade à insulina. Ainda assim, a maioria dos estudos está focada na análise da diferenciação e da função do adipócito, bem como nas alterações sofridas nas situações patológicas. Poucos estudos analisam o papel da toxicidade mitocondrial na diferenciação e função dos adipócitos. ${ }^{(34)}$

Os pré-adipócitos sofrem maturação em duas etapas: diferenciação e hipertrofia(figura 4). Durante o estágio inicial da maturação, encontramos um número elevado de mitocôndrias que leva ao aparecimento de pequenos adipócitos altamente sensíveis à insulina e produtores de adiponectina. Em contrapartida, os adipócitos já em fase avançada de maturação sofrem uma 
hipertrofia, perdem sua capacidade funcional, tornam-se resistentes à insulina e apresentam cada vez menos mitocôndrias. (34)

Figura 4. Etapas da diferenciação e maturação da célula adiposa.

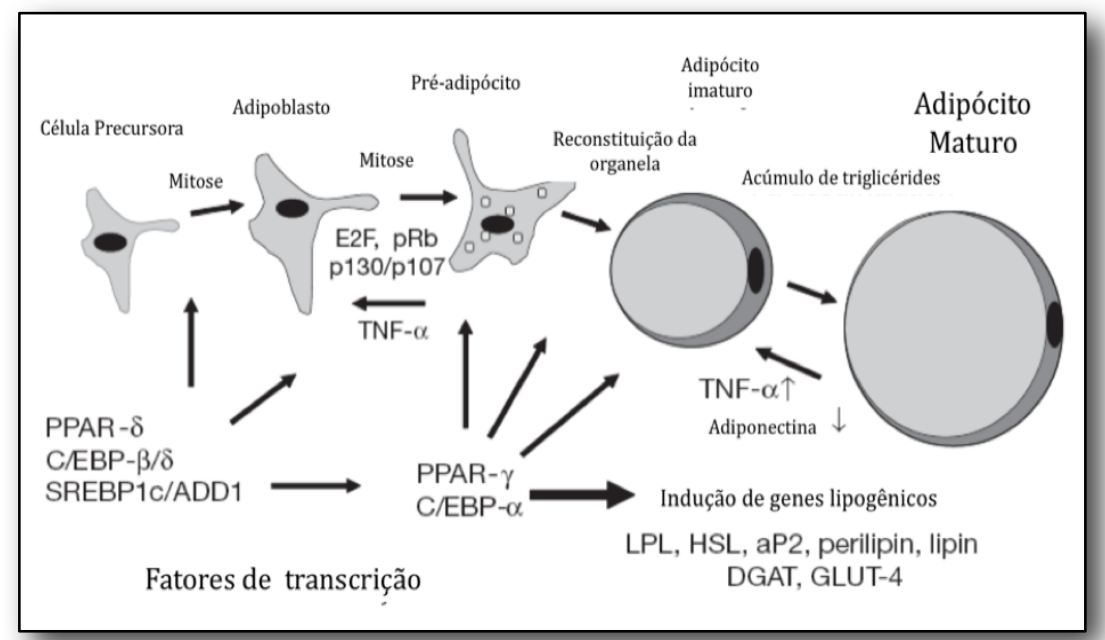

Os mecanismos exatos pelos quais os IPs ou os ITRNs provocam as alterações de gordura ainda não estão completamente elucidados. Informações acumuladas ao longo dos últimos 15 anos sustentam a hipótese de que os eventos adversos relacionados aos ITRNs são impulsionados primariamente pela toxicidade mitocondrial (TM) (35). Os ITRNs inibem seletivamente o mtDNA, mas esta inibição isoladamente não contribui completamente para a TM, o que sugere que outros mecanismos estejam envolvidos ${ }^{(27,36)}$. A disfunção mitocondrial pode prejudicar a função dos adipócitos, via aumento dos níveis das espécies oxigênio-reativas (ROS) e redução da produção do ATP (36). Estas alterações podem levar a distúrbios oxidativos no metabolismo dos lípides, favorecendo o acúmulo de lípides e a lipotoxicidade (27). As toxicidades mediadas pelos ITRNs provavelmente interagem com as alterações associadas aos IPs e ao próprio HIV, e contribuem para o aumento da apoptose e lipólise dos adipócitos, 
resultando numa diminuição do tamanho dos adipócitos e subseqüentemente num fenótipo lipoatrófico (figura 5).

Figura 5. Mecanismos envolvidos na patogênese da lipodistrofia associada ao HIV.

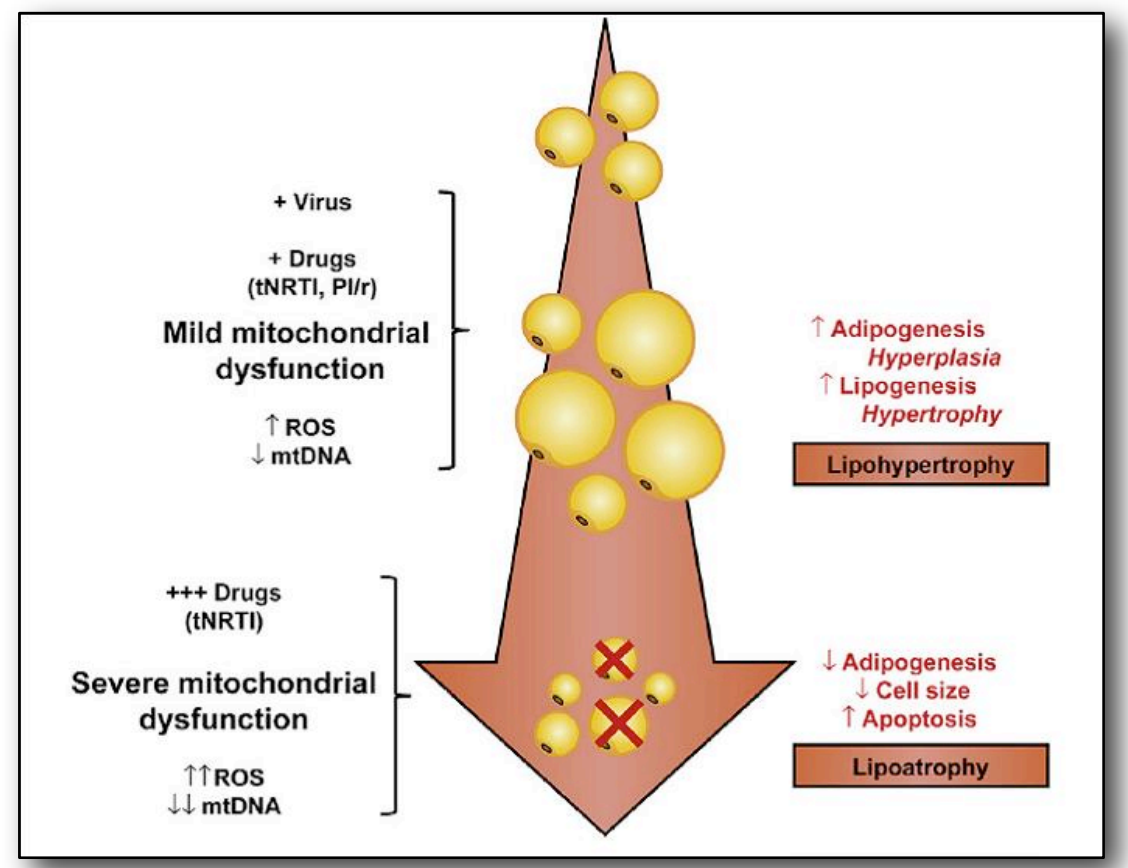

As alterações patológicas observadas no tecido adiposo dos pacientes com lipoatrofia incluem: aumento da apoptose, da fibrose, no nível da citocinas inflamatórias, infiltração por macrófagos, pleomorfismo dos adipócitos e perda da arquitetura tecidual (36). A lipoatrofia começa a se desenvolver antes do aparecimento dos sinais clínicos. Ela é guiada pelas mudanças moleculares precoces até a perda de gordura visível clinicamente. As alterações moleculares mitocondriais podem ser detectadas nas primeiras quatro semanas de TARV e estudos longitudinais têm demonstrado que elas ocorrem dentro de um ano do início do uso dos ITRN (37).

Entre os IP, o uso do nelfinavir (NFV) e do ritonavir (RTV) demonstraram a diminuição da expressão dos marcadores associados à 
diferenciação dos adipócitos (cellular retinoic acid-binding protein 1 CRABP-1 e peroxisome proliferator-activated receptor gamma - PPARY). Em contraste, observou-se que a utilização do IDV em concentrações $\leq 20$ $\mu \mathrm{M}$ pode diminuir, não causar alteração ou até aumentar a diferenciação dos adipócitos ou a expressão dos marcadores destas células, enquanto que a exposição ao saquinavir (SQV) não tem efeito na diferenciação dos mesmos $(37,10)$.

O tamanho dos adipócitos é determinado pela quantidade de lípides no reservatório intracelular. In vitro, as reservas intracelulares são depletadas nos adipócitos expostos aos IP e aos ITRN. Nos ITRN, este efeito é mais marcado nos pacientes expostos ao AZT e d4T. Com os IP, este efeito nos lípides intracelulares varia consideravelmente, com o NFV = SQV > RTV > IDV = AMP (amprenavir), em termos de capacidade de acúmulo intracelular de lípides ${ }^{(37)}$. Este tamanho também pode ser reduzido pela lipólise, a qual resulta na liberação de triglicérides para a circulação. In vitro, a exposição ao NFV levou a um aumento na lipólise e o mesmo efeito foi observado em outros estudos com RTV e SQV na concentração de 10 $\mu \mathrm{M}$. Tal efeito in vivo poderia contribuir para a lipoatrofia e hipertrigliceridemia ${ }^{(37)}$.

O aumento da apoptose (morte celular programada) também tem sido demonstrado in vivo, em biópsias de tecido adiposo de indivíduos com lipodistrofia e nas culturas de adipócitos expostos a vários IP, AZT ou d4T. Além da apoptose, a citotoxicidade direta dos adipócitos também ocorre in vitro com a exposição aos IP, mas não aos ITRN (37). 
Algumas proteínas virais acessórias têm sido relacionadas à fisiopatologia da lipodistrofia. A proteína Vpr inibe a atividade do PPARY podendo contribuir para a resistência insulínica e para a apoptose do adipócito assim como antagoniza o fator de transcrição da insulina (FKHR) favorecendo a resistência insulínica. Já a proteína Tat eleva a sensibilidade tecidual aos glicocorticóides provocando alterações do tecido gorduroso semelhante à Síndrome Cushingóide. (10)

Outros mecanismos importantes na patogênese da lipoatrofia estão associados aos elevados níveis de citocinas inflamatórias. Os monócitos são relativamente resistentes à infecção pelo HIV, enquanto os macrófagos diferenciados são altamente suscetíveis. Os macrófagos teciduais infectados pelo HIV-1 liberam citocinas pró-inflamatórias. Essa inflamação sistêmica associada à infecção pelo HIV promove a migração de monócitos através do endotélio vascular, levando a um aumento do número de macrófagos ativados no tecido gorduroso. Desta forma, a severidade da infecção pelo HIV esta associada ao aumento da prevalência de lipodistrofia, provavelmente como conseqüência da presença persistente de macrófagos infectados pelo HIV causando um processo inflamatório local. (34) O tecido lipoatrófico dos indivíduos infectados pelo HIV apresenta expressão aumentada dos níveis de TNF- $\alpha$, citocina que induz a apoptose das células de gordura ${ }^{(38)}$.

Também se verifica o papel de alguns hormônios relacionados diretamente com o tecido adiposo na patogênese da lipodistrofia, especialmente a adiponectina e a leptina. A adiponectina é um hormônio 
derivado do adipócito cujas funções são: sensibilizar a insulina reduzindo os níveis de triglicérides e inibir a gluconeogênese hepática. A deficiência de adiponectina tem sido implicada na obesidade, na resistência à insulina e no diabetes tipo 2 na população em geral e também tem sido correlacionada inversamente com acúmulo de gordura visceral em pacientes HIV com lipodistrofia. A presença de baixos níveis plasmáticos de adiponectina e a sua menor expressão no tecido adiposo é observada após a administração de IP (pela inibição da adipogênese). Esta também tem sido observada com o uso de estavudina e zidovudina. Estudos in vitro têm mostrado que a expressão do gene regulador da adiponectina é mais diminuída pelos IP do que pelos ITRN. As concentrações de adiponectina também podem ser reduzidas pelas citocinas pró-inflamatórias TNF- $\alpha$ e IL-6.(39) A IL-6 é a interleucina mais comum no tecido adiposo, mas também está presente na circulação sangüínea e no líquido cérebro espinhal. É possível que a secreção aumentada de certas citocinas como o TNF- $\alpha$ e IL-6 no tecido adiposo e uma maior da atividade sistêmica pró-inflamatória, possam ter um papel no remodelamento do tecido adiposo e das anormalidades metabólicas observadas nos pacientes com lipodistrofia associada ao HIV. (39)

A leptina é um hormônio derivado dos adipócitos e os seus níveis plasmáticos se correlacionam diretamente com a quantidade do tecido adiposo (tecido adiposo subcutâneo, melhor do que o tecido adiposo visceral). É responsável pela regulação da homeostase de energia e tem efeito periférico na oxidação de ácidos graxos. Indivíduos com lipoatrofia 
apresentam redução da síntese de leptina e diminuição da gordura subcutânea enquanto os pacientes com lipohipertrofia exibem níveis elevados de leptina devido à resistência à mesma. Este estado de resistência à leptina pode também estar associado à síndrome metabólica e a RI nos pacientes infectados pelo HIV com lipohipertrofia. (39)

\subsection{Alterações metabólicas associadas à Lipodistrofia}

A grande variedade de sintomas e sinais associados à chamada síndrome metabólica (SM) tornou difícil defini-la com precisão. Três grupos diferentes organizaram as informações para promover critérios diagnósticos para a síndrome metabólica: a Organização Mundial de Saúde (OMS), a American Association of Clinical Endocrinologists (AACE) e o National Cholesterol Education Program (NCEP), por meio das recomendações do III Adult Treatment Panel (ATP III). O ATP III identificou cinco componentes da Síndrome Metabólica relacionados à doença cardiovascular: obesidade abdominal, dislipidemia aterogênica, aumento da pressão arterial, resistência insulínica com ou sem intolerância à glicose, estados próinflamatório e pró-trombótico.

Neste estudo a SM pode ser caracterizada pela combinação da dislipidemia, resistência insulínica e intolerância à glicose, definindo um conjunto de fatores de risco lipídicos e não lipídicos que identifica pacientes sob risco aumentado de doença cardiovascular (DCV).(40) A lipodistrofia, associada às alterações metabólicas, descrita nos indivíduos tratados com IP e com ITRN, esta relacionada com a SM. ${ }^{(41)} \mathrm{A}$ obesidade central e a 
resistência insulínica são dois dos seus principais achados. A medida da circunferência abdominal permite identificar portadores de obesidade androgênica ou visceral. A medida da cintura representa um marcador de risco para alterações metabólicas, independente do índice de massa corporal (IMC). (42) Muitos indivíduos com a síndrome metabólica desenvolvem diabetes mellitus tipo 2. Os portadores da síndrome metabólica apresentam risco relativo de aterosclerose de duas a três vezes o da população normal. ${ }^{(42)}$

Um aumento significativo da prevalência da síndrome metabólica nos pacientes infectados pelo HIV em uso de TARV comparado com a população normal tem sido descrito em vários estudos. ${ }^{(43,44)}$ Uma revisão recente que analisa diversos estudos sobre SM em pacientes HIV estima a prevalência em torno de $7-45 \%$ dependendo do desenho do estudo e dos parâmetros $\operatorname{avaliados}^{(45)}$.

A dislipidemia é caracterizada pela hipertrigliceridemia, aumento do colesterol total e LDL-c, diminuição do HDL-c e níveis elevados de ácidos graxos esterificados ${ }^{(27)}$.

Estudos têm mostrado que a RI associada à obesidade e DM tipo II é mediada a nível dos adipócitos (27).

A maior parte dos IP exerce efeito direto nos adipócitos, prejudicando a captação de glicose induzida pela insulina. Esta ação pode limitar a capacidade de armazenamento de gordura do tecido adiposo e provocar o efeito lipotóxico pelo desvio dos lípides circulantes e da dieta para outros tecidos, enquanto ocorre o prejuízo da ação da insulina. Este efeito pode 
ser aumentado pela ação direta dos IP nos tecidos periféricos, tais como o muscular. Nestes, a ação desses medicamentos também prejudica a função da insulina (27).

\subsection{Diagnóstico}

O diagnóstico da lipodistrofia associada ao HIV é baseado na concordância entre as queixas relatadas pelo paciente e a avaliação feita pela equipe de saúde. Algumas ferramentas podem ser utilizadas para facilitar esse diagnóstico como, por exemplo, a antropometria e os exames de imagem, como a densitometria (Dual energy X-ray absorptiometry DEXA), a tomografia computadorizada (TC) e a ressonância nuclear magnética (RNM). ${ }^{(46,47)}$

Os critérios diagnósticos devem ser específicos e sensíveis, e considerar a distribuição regional do tecido adiposo entre os membros e abdome, assim como a distribuição entre o compartimento subcutâneo e visceral.

$\mathrm{Na}$ antropometria, os principais critérios para avaliar a lipodistrofia associada ao HIV são: peso, altura e IMC. No entanto, estes critérios não são suficientes para distinguir lipoatrofia ou lipohipertrofia da obesidade. Além disso, alguns quadros de lipodistrofia, principalmente nos pacientes com a síndrome mista, não são acompanhados por alterações significativas no peso ou no IMC. ${ }^{(48)}$

As medidas da circunferência do braço, pescoço, coxa, cintura e quadril são utilizadas para identificar a lipodistrofia. Embora não exista um valor confiável que reflita a presença ou ausência de redistribuição da 
gordura, alguns autores têm utilizado a relação cintura/quadril superior a 0,95 nos homens e de 0,85 ou 0,90 em mulheres, como indicadores da lipodistrofia. ${ }^{(11,48,49,50)}$

As dobras cutâneas também podem ser utilizadas para estimar a composição corporal em pacientes com lipodistrofia obtidas a partir de medidas com adipômetros. Existe uma correlação entre as medidas antropométricas e os resultados da DEXA e da TC para avaliar a massa de gordura corporal. ${ }^{(11,46,47,50)}$

A medida objetiva da composição de gordura corporal de acordo com a região e compartimentos em pacientes HIV+ com lipodistrofia pode ser feita através da ultra-sonografia (USG), DEXA, TC e a RNM. No entanto, a maioria desses métodos não é utilizada na prática médica devido ao elevado custo e à falta de padronização. ${ }^{(46,50)}$

A medida do tecido adiposo subcutâneo (TAS) na região malar utilizando a ultrassonografia é empregada em pesquisas para avaliar a resposta ao tratamento corretivo e tem uma sensibilidade de $88 \%$ e especificidade de $84 \%$, de acordo com critérios diagnósticos clínicos. A realização da ultrassonografia para avaliar a lipodistrofia em outras regiões é menos sensível (51).

O DEXA permite avaliar a distribuição de massa gorda no tronco e membros, ou calcular a composição de gordura total. Com o DEXA, no entanto, é difícil determinar a distribuição de gordura entre os compartimentos da mesma região. A TC e a RNM são os métodos de referência utilizados na investigação radiológica, pois fornecem uma 
representação tridimensional da distribuição e do volume da massa gorda. Ambos permitem analisar a distribuição do tecido adiposo entre os compartimentos específicos a serem avaliados. A partir dos resultados, a relação entre tecido adiposo visceral (TAV) / tecido adiposo subcutâneo (TAS) e a relação entre TAV / gordura total podem ser calculadas. Uma relação de TAV / gordura total superior a 0,4 é considerada anormal. Entretanto, devido ao custo elevado, essas modalidades não são rotineiramente empregadas. ${ }^{(11,46,50)}$

Análise por bioimpedância elétrica tem sido utilizada como ferramenta diagnóstica quantitativa para lipodistrofia; todavia, não fornece dados sobre a distribuição de gordura regional, o que prejudica a avaliação da lipodistrofia ${ }^{(11) .}$

\subsection{Tratamento}

Não existe até o momento nenhum tratamento definitivo para as alterações morfológicas provocadas pela lipodistrofia. Várias opções terapêuticas têm sido exploradas com diversos graus de sucesso a fim de reduzir os danos causados pela lipodistrofia $(46,52,53,54)$.

- Mudanças no estilo de vida (exercício físico, orientação nutricional)

- Redução na exposição às drogas (retardamento do início da terapia anti-retroviral e modificação da TARV)

- Tratamento farmacológico

- Tratamentos cirúrgicos. 
Sabe-se que as alterações da redistribuição de gordura corporal associadas ao tratamento antirretroviral, uma vez estabelecidas, são irreversíveis. Não existem estratégias medicamentosas eficazes para recuperar o tecido gorduroso acometido, com isso, a cirurgia torna-se praticamente a única maneira de corrigir essas alterações.

Com o objetivo de realizar procedimentos cirúrgicos para minimizar os danos causados pela lipodistrofia, o Ministério da Saúde do Brasil publicou as "Diretrizes de Indicação para Tratamento de Lipodistrofia em Portadores de HIVIAIDS". O Brasil é o primeiro país a oferecer gratuitamente cirurgias reparadoras para portadores de HIV com lipodistrofia. ${ }^{(55)}$

O tratamento cirúrgico das alterações corporais foi incluído no SUS em 2004, por Portaria Ministerial $n^{\circ} 2.582$, para portadores de aids em uso de terapia antirretroviral (46). Em 2005, a Portaria $n^{\circ} 118$, estabeleceu os protocolos de indicação das cirurgias reparadoras. Em 2007, a Portaria Conjunta $n^{\circ} 02$ estabeleceu as normas para credenciamento das instituições de saúde, para a realização dos procedimentos. Em 2009 a Portaria Conjunta $n^{\circ} 01$ revogou as anteriores e realizou uma série de ajustes que se fizeram necessários em relação às normas para o credenciamento dos hospitais e ambulatórios, de estrutura física e de recursos humanos, para o tratamento reparador das alterações corporais relacionadas à lipodistrofia. $(55,56)$ 


\section{Justificativa para a realização do projeto}

A lipodistrofia associada aos pacientes portadores do HIV é uma condição patológica prevalente numa parcela significativa dos mesmos. Vários estudos tem sido desenvolvidos com a finalidade de identificar, descrever e propor estratégias de prevenção e tratamento da lipodistrofia. Desta maneira, visamos identificar as características clínicas dos pacientes com HIV e lipodistrofia que procuraram um tratamento cirúrgico para as mesmas. Este tratamento é realizado no Hospital Heliópolis, o qual há 6 anos tem um serviço de atendimento aos pacientes com lipodistrofia para realização de procedimentos cirúrgicos reparadores. O serviço de lipodistrofia do Hospital Heliópolis foi o pioneiro no Brasil a oferecer o tratamento cirúrgico para correção da lipodistrofia.

As informações deste estudo poderão contribuir para a formulação de estratégias de prevenção e tratamento desta condição associada ao HIV/ AIDS. 


\section{Objetivos}

\subsection{Objetivo Geral}

Descrever algumas características clínicas e laboratoriais de indivíduos com HIVIAIDS e lipodistrofia encaminhados para realização de procedimentos corretivos cirúrgicos no Hospital Heliópolis-SP da Secretaria de Saúde do Estado de São Paulo.

\subsection{Objetivos Específicos}

4.2.1 Avaliar os dados laboratoriais relativos ao colesterol total, HDL colesterol, LDL colesterol, triglicérides, glicemia, contagem da carga viral e contagem de células CD4;

4.2.2 Descrever a relação do tempo de diagnóstico da infecção pelo HIV e o tempo de exposição a drogas ARV com a lipodistrofia;

4.2.3 Descrever a composição corporal utilizando a análise antropométrica (índice de massa corpórea), a composição corporal de depósito adiposo pelas pregas cutâneas, os indicadores da distribuição de gordura através da aferição da circunferência da cintura e do quadril; 
4.2.4 Descrever a prevalência, na amostra estudada, das alterações relacionadas à síndrome de lipodistrofia como: lipohipertrofia abdominal, lipohipertrofia cervical (giba), lipohipertrofia de mamas, lipohipertrofia dorsal, lipoatrofia facial, lipoatrofia de membros superiores e inferiores e lipoatrofia glútea;

4.2.5 Avaliar a presença de associação das alterações metabólicas e alterações de distribuição de gordura corporal nesta população.

4.2.6 Avaliar a associação das formas clínicas da lipodistrofia com as medidas antropométricas preditoras de risco aumentado para doenças cardiovasculares (circunferência da cintura e relação cintura-quadril). 


\section{Métodos}

\subsection{Desenho do Estudo}

Trata-se de um estudo descritivo e analítico retrospectivo transversal para estudar as alterações relacionadas à lipodistrofia em pacientes atendidos no programa de lipodistrofia do Hospital Heliópolis de 01 de abril de 2006 à 31 de março de 2008.

Todos os dados foram obtidos através dos prontuários de atendimento médico e transcritos para uma ficha clínica padrão. (anexo I)

\subsection{Casuística}

Foram levantados dados dos prontuários de 341 indivíduos com HIV/ AIDS e lipodistrofia atendidos no Programa de Lipodistrofia do Hospital Heliópolis no período compreendido entre 01 de abril de 2006 à 31 de março de 2008 encaminhados da rede de atendimento a pacientes com HIVIAIDS para serem submetidos às correções cirúrgicas da lipodistrofia segundo a Portaria Conjunta $n^{\circ} 2$ do Ministério da Saúde - 27 de março de 2007.

Os dados referentes aos exames de CD4, carga viral, colesterol total e frações, triglicérides e glicemia foram transcritos das cópias dos exames que estavam arquivados nos prontuários e foram enviados dos serviços de origem dos indivíduos selecionados. O mesmo se aplicou aos dados antropométricos e aos dados de atividade física que foram obtidos através do instrumento de avaliação nutricional realizado pela nutricionista do ambulatório de lipodistrofia. A avaliação da síndrome metabólica já é 
realizada de rotina no ambulatório de lipodistrofia de acordo com os critérios do NCEP e esse dado foi transcrito diretamente do prontuário.

\subsection{Critérios de inclusão}

Foram incluídos todos os pacientes que apresentavam pelo menos os seguintes dados

- Data do diagnóstico do HIV

- Esquema antirretroviral atual

- Tempo de uso do esquema ARV atual

- Avaliação antropométrica

- Dados laboratoriais de CD4, carga viral, colesterol total, HDL colesterol, LDL colesterol, triglicérides e glicemia num período máximo de três meses anteriores ao atendimento no programa de lipodistrofia do Hospital Heliópolis

- Presença ou não de síndrome metabólica

\subsection{Critérios de Exclusão}

Foram excluídos os indivíduos para os quais não se obteve todos dados relativos às variáveis descritas nos critérios de inclusão.

\subsection{Aspectos éticos}

O projeto de pesquisa foi apresentado e aprovado pelo Comitê de Ética em Pesquisa do Hospital Heliópolis, pelo Comitê de Ética e Pesquisa 
do Departamento de Doenças Infecciosas e Parasitárias do HCFMUSP e pela Comissão de Ética para Análise de Projetos de Pesquisa do HCFMUSP.

\subsection{Materiais e métodos}

\subsubsection{Avaliação antropométrica}

Os parâmetros antropométricos descritos a seguir foram obtidos pelo mesmo observador capacitado para tal atividade (única nutricionista). Todos os dados foram realizados em triplicada no mesmo momento adotando-se o valor médio.

Peso: o peso foi aferido em balança digital, do tipo plataforma, com capacidade mínima de 1,25 kg e máxima de 150 kg com variação mínima de 50g. Para esta mensuração, os pacientes foram posicionados em pé, descalços, e com o mínimo de roupa possível, permanecendo ereto, com os pés juntos ao centro da plataforma, braços ao longo do corpo. (57)

Estatura: a estatura foi determinada com auxílio de uma fita métrica colocada na parede com capacidade de $2 \mathrm{~m}$ e $1 \mathrm{~cm}$ de graduação. Para a obtenção desta medida, todos os pacientes ficaram descalços e sem meias. Foram medidos em posição supina, sempre com o corpo e joelhos esticados, pés a $90^{\circ}$, cabeça ereta, formando uma superfície horizontal com o esquadro móvel do antropômetro. (57) 
Índice de Massa Corporal (IMC) (Índice de Quetelet.)

Com o peso atual e a altura, obteve-se o IMC, que foi calculado a partir da seguinte formula: ${ }^{(58)} I M C=$ peso atual/estatura ${ }^{2}\left(\mathrm{~kg} / \mathrm{m}^{2}\right)$

Os pontos de corte de IMC considerados para o diagnóstico nutricional foram preconizados pela Organização Mundial da Saúde - OMS, 1995 (Quadro 1) ${ }^{(59)}$ e Lipschitz, 1994 (Quadro 2) ${ }^{(60)}$ para adultos e idosos, respectivamente e foram agrupados em 3 grupos: desnutrição, eutrofia e excesso de peso.

Quadro 1 - Classificação do estado nutricional de indivíduos com menos de 60 anos, de acordo com o IMC.

\begin{tabular}{cc}
\hline IMC $\left(\mathbf{k g} / \mathbf{m}^{2}\right)$ & Estado Nutricional \\
\hline$<18,5$ & Desnutrição \\
$18,5-24,9$ & Eutrofia \\
$\geq 25,0$ & Excesso de Peso \\
\hline
\end{tabular}

Fonte: OMS, 1995(59)

Quadro 2 - Classificação de estado nutricional de indivíduos com mais de 60 anos, de acordo com o IMC.

\begin{tabular}{cc}
\hline IMC $\left(\mathbf{k g} / \mathbf{m}^{2}\right)$ & Estado Nutricional \\
\hline$<22,0$ & Desnutrição \\
$22,0-27,0$ & Eutrofia \\
$\geq 27,0$ & Excesso de Peso
\end{tabular}

Fonte: Lipschitz, $1994^{(60)}$

Circunferência do Braço (CB): aferida com uma fita métrica inextensível do ponto médio entre o acrômio da escápula e o olécrano da ulna. Para a obtenção desse ponto o paciente permaneceu em pé, com o braço fletido a 
$90^{\circ}$ e, com a fita mediu-se a distância entre os 2 pontos, sendo que o ponto eqüidistante é marcado com uma caneta. Para se obter a $\mathrm{CB}$, o paciente relaxou o braço e circundou com a fita, sem comprimir as partes moles. A leitura foi realizada no centímetro mais próximo. Essa medida é realizada no braço direito para todos os sujeitos.

Circunferência da cintura e do quadril: as circunferências da cintura e do quadril foram mensuradas com precisão de $0,1 \mathrm{~cm}$ utilizando-se uma fita antropométrica inextensível de fibra de vidro. A circunferência da cintura foi obtida durante a expiração normal, sendo circundada a menor circunferência horizontal localizada abaixo das costelas e acima da cicatriz umbilical. A circunferência do quadril foi medida circundando o quadril na região de maior perímetro entre a cintura e a coxa, com o indivíduo usando roupas finas.

Dobras cutâneas: foram medidas as dobras cutâneas do tríceps, bíceps, subescapular e suprailíaca no braço direito, utilizando-se adipômetro do tipo Lange Skinfold Caliper (Cambridge Scientific Industries Inc.), que mantém pressão constante de $10 \mathrm{~g} / \mathrm{mm}^{2}$. As medidas foram feitas seguindo a padronização de Durnin \& Rahaman. (61)

- A dobra cutânea do tríceps (DCT) foi medida na parte posterior do antebraço, sobre o músculo triciptal, no ponto médio entre o acrômio e o olécrano, determinada da mesma maneira descrita para medir a CB. Estando o braço relaxado, pinçou-se a pele e o tecido 
subcutâneo entre o polegar e o indicador e aplicou-se o adipômetro a $1 \mathrm{~cm}$ abaixo dos dedos que pinçavam a prega e, sem soltar, fizeramse 3 leituras, utilizando-se a média das 2 mais próximas, no milímetro mais próximo.

- A dobra cutânea do bíceps (DCB) foi medida na parte anterior do antebraço, sobre a maior elevação do músculo bíceps, aplicando-se o adipômetro e procedendo-se à leitura conforme a técnica descrita anteriormente.

- A dobra cutânea subescapular (DCS) foi medida logo abaixo da extremidade da escápula. A pele e o tecido subcutâneo foram pinçados logo abaixo da borda da escápula e a prega foi angulada em $45^{\circ}$ a partir do plano horizontal, onde se colocou o adipômetro, $1 \mathrm{~cm}$ abaixo dos dedos que pinçavam a prega, e fizeram-se 3 leituras, utilizando-se a média das duas mais próximas, no milímetro mais próximo.

- A dobra cutânea supra-ilíaca (DCSI) foi medida logo acima da crista ilíaca, seguindo-se a linha axilar média. A pele e o tecido subcutâneo foram pinçados e o adipômetro aplicado a $1 \mathrm{~cm}$ dos dedos, e a leitura foi feita conforme o procedimento descrito anteriormente.

Percentil CB: essa medida corresponde ao compartimento adiposo somado ao muscular mais o osso do braço do indivíduo. Utilizou-se como referência a tabela de percentis de Frisancho (1981). (62) Na rotina essa medida só é 
utilizada para classificação do paciente em 4 categorias conforme quadro 3 . Neste estudo, classificamos os pacientes em 3 categorias:

- Desnutrição (agrupando a desnutrição com o risco para desnutrição)

- Eutrofia

- Obesidade

Quadro 3 - Classificação do estado nutricional de acordo com os percentis da circunferência do braço

\begin{tabular}{cc}
\hline Percentil & Classificação \\
\hline$<5$ & Desnutrição \\
$5-15$ & Risco para Desnutrição \\
$15-85$ & Eutrofia \\
$>85$ & Obesidade \\
\hline
\end{tabular}

Fonte: Frisancho, $1981^{(62)}$

Percentil CMB: a circunferência muscular do braço (CMB) é utilizada para avaliar a reserva muscular ou massa corpórea magra (massa muscular e osso), tendo como referência os percentis encontrados na tabela de Frisancho (1981). ${ }^{(62)}$ A circunferência muscular do braço (CMB) foi calculada através da formula abaixo:

CMB $=$ CB $-\pi$ X DCT $\quad(\pi=3.14$, CB em $\mathrm{cm}$ e DCT em mm $)$

$\mathrm{Na}$ análise deste estudo utilizamos os percentis de acordo com a classificação do quadro 4. 
Quadro 4 - Classificação do estado nutricional de acordo com os percentis da circunferência muscular do braço.

\begin{tabular}{cc}
\hline IMC $\left(\mathbf{k g} / \mathbf{m}^{2}\right)$ & Estado Nutricional \\
\hline$<10$ & Desnutrição \\
$10-90$ & Eutrofia \\
$>90$ & Obesidade \\
\hline
\end{tabular}

Fonte: Frisancho, $1981^{(62)}$

Em pacientes com HIVIAIDS, a CMB usualmente encontra-se diminuída, podendo indicar degradação da proteína muscular (especialmente de aminoácidos de cadeia ramificada), que ocorre juntamente com a depleção de potássio.

Porcentagem de Gordura Corporal: a determinação da porcentagem de gordura corporal foi realizada por meio da seguinte fórmula:

$(\%)$ de gordura $=((4,95 /$ Densidade Corporal $)-4,50) \times 100$

A densidade corporal foi obtida pela seguinte equação de regressão linear: Densidade $=(C-M) \times \log X$; onde $C$ e $M$ são coeficientes de densidade corporal, de acordo com a idade e sexo, e X é a soma das 4 pregas cutâneas (bíceps, tríceps, subescapular e supra-ilíaca) segundo a equação de Durnin \& Womersley, 1974. ${ }^{(63)}$ A gordura corporal foi calculada multiplicando-se o peso atual pela \% de gordura corporal obtida. Consideraram-se como excesso de gordura corporal os homens que apresentaram percentuais acima de $15 \%$ e as mulheres, acima de $23 \%$, segundo os critérios de Lohman et al., 1992. (64) 
Indicadores da distribuição de gordura corporal: foi calculada a Relação Cintura-Quadril (RCQ) para identificar o tipo de distribuição de gordura sendo utilizados os pontos de corte do World Health Organization (WHO), $2000^{(49)}$ onde homens com valores 0,90 e mulheres 0,80 foram considerados como risco aumentado para o desenvolvimento de doenças crônicas. Também foi utilizada a circunferência de cintura isoladamente com pontos de corte de $>80 \mathrm{~cm}$ para mulheres e $>94 \mathrm{~cm}$ para homens como risco aumentado para doenças metabólicas decorrentes da deposição de gordura no abdômen de acordo com as recomendações para terapia antirretroviral em adultos e adolescentes infectados pelo HIV 2007/2008 - Ministério da Saúde. ${ }^{(65)}$

\subsubsection{Avaliação bioquímica}

Os dados dos exames laboratoriais selecionados foram obtidos através das cópias dos exames encaminhados dos serviços de tratamento de HIVIAIDS arquivados nos prontuários. Os dados são: dosagem de glicemia de jejum, dosagem de colesterol total e frações, dosagem de triglicérides.

\subsubsection{Análise dos esquemas antirretrovirais utilizados no momento do encaminhamento}

$\mathrm{Na}$ avaliação do tratamento antirretroviral foi levado em conta o tempo de uso do último esquema. Foram identificados os esquemas e classificados em 5 grupos: 
- Grupo A: ITRN+ITRNN

- Grupo B: ITRN+IP

- Grupo C: ITRN

- Grupo D: ITRN+ITRNN+IP

- Grupo E: Outras associações

Os ARV de acordo com as classes são:

- Inibidores da Transciptase Reversa Análogos (ITRN): zidovudina (AZT), lamivudina (3TC), estavudina (d4T), didanosina (ddl), tenofovir (TDF)

- Inibidores da Transcriptase Reversa Não Análogos (ITRNN): efavirenz (EFZ), nevirapina (NVP), etravirina (ETV)

- Inibidores da Protease: indinavir (IDV), lopinavir/ritonavir (LPV/r), atazanavir (ATV), ritonavir (RTV), saquinavir (SQV), fosamprenavir (FPV), amprenavir (APV), darunavir (DRV)

- Inibidores da Fusão (IF): enfuvirtide (T20)

- Inibidores da Integrase (II): raltegravir (RAL)

\subsubsection{Classificação da lipodistrofia}

A lipodistrofia foi classificada de acordo com a literatura em 3 grupos:

- Lipoatrofia: face, membros superiores, membros inferiores, glúteo

- Lipoacumulação: abdome, dorso, dorso-cervical (giba), tórax/mama, submento, púbis, outros (lipomas).

- Forma mista: associação de lipoatrofia e lipoacumulação 


\subsubsection{Classificação da Síndrome Metabólica}

A Síndrome Metabólica foi classificada de acordo com o National Cholesterol Education Program (NCEP) por meio das recomendações do III Adult Treatment Panel (ATP III). (40) Os critérios da síndrome metabólica encontram-se no Quadro 5. De acordo com este esquema, um indivíduo com três destes cinco critérios apresenta a síndrome metabólica.

Quadro 5 - Critérios da síndrome metabólica segundo o National Cholesterol Education Program (NCEP) - ATP III.

\begin{tabular}{ll}
\hline Variável & ATP III \\
\hline Circunferência abdominal & $\begin{array}{l}\text { Homem } \geq 102 \mathrm{~cm} \\
\text { Mulher } \geq 88 \mathrm{~cm} \\
\geq 150 \mathrm{mg} / \mathrm{dL}\end{array}$ \\
Triglicérides & $\geq 110 \mathrm{mg} / \mathrm{dL}$ \\
Glicemia & Homem $<40 \mathrm{mg} / \mathrm{dL}$ \\
HDL colesterol & $\begin{array}{l}\text { Mulher }<50 \mathrm{mg} / \mathrm{dL} \\
\text { Pressão arterial }\end{array}$ \\
\hline
\end{tabular}

Fonte: NCEP ATP III (40)

\subsection{6 - Classificação do Nível de Atividade Física ${ }^{(66)}$}

Inativo - pessoa que pratica atividade física moderada ou vigorosa por menos de 10 minutos contínuos durante a semana.

Insuficientemente ativo - Realiza atividade física por pelo menos 10 minutos por semana, não atingindo as recomendações de atividades moderadas ou vigorosas

Ativo - pessoa que pratica atividade física moderada por pelo menos 30 minutos, 5 vezes por semana ou atividade física vigorosa por pelo menos 20 minutos, 3 vezes por semana. 
Neste estudo agrupamos os 3 grupos em 2: sedentário (inativo e insuficientemente ativo) e ativo.

\subsection{Métodos estatísticos}

A análise estatística compreendeu as seguintes etapas

1. Estudo da distribuição de freqüência absoluta e relativa de todas as variáveis pesquisadas.

2. As variáveis quantitativas contínuas foram agrupadas em categorias de acordo com o recomendado pela literatura.

3. Testes de associação entre as variáveis desfecho e independentes. Para isso foram empregados o teste exato de Fisher ou o teste do qui-quadrado, em conformidade com a distribuição dos dados na tabela de contingência. Foi considerado significante um $p<0,05$ para teste bicaudal.

4. Todos esses resultados são apresentados em tabelas que seguem as normas da pós graduação da Faculdade de Medicina USP. 


\section{Resultados}

Neste estudo foram incluídos 341 pacientes atendidos no Programa de Lipodistrofia do Hospital Heliópolis para correções cirúrgicas. Estes pacientes foram encaminhados dos centros de tratamento para pacientes HIV do Estado de São Paulo, em sua maioria, conforme figura 6 e cumpriam os critérios de inclusão e exclusão.

Figura 6 - Distribuição da população estudada atendida no Programa de Lipodistrofia do Hospital Heliópolis-SP por Direção Regional de Saúde (DRS) no Estado de São Paulo no período de 01 de abril de 2006 à 31 de março de 2008.

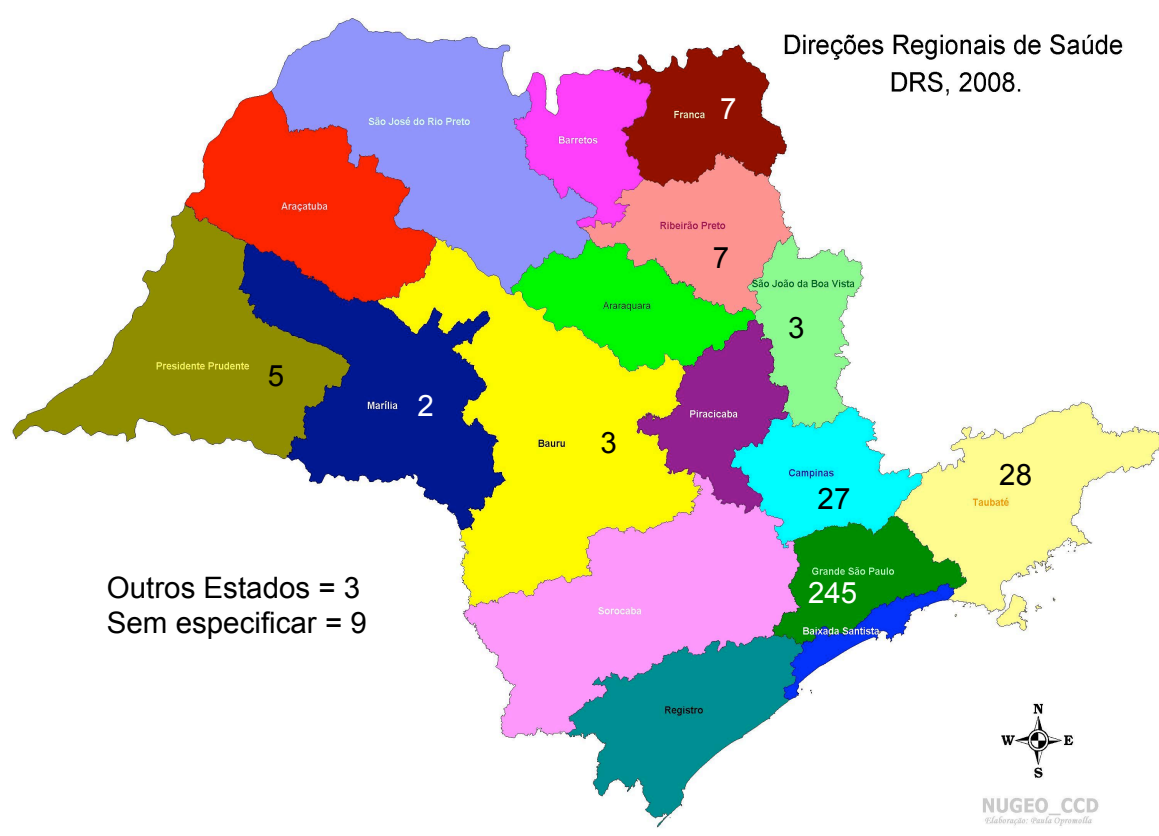


Tabela 1 - Distribuição da população estudada de acordo com as características demográficas, tempo de diagnóstico do HIV, tabagismo, atividade física e síndrome metabólica, abril de 2006 a março de 2008

\begin{tabular}{lccc}
\hline Variável & Categoria & N & $\%$ \\
\hline Sexo & masculino & 143 & 41,9 \\
& feminino & 198 & 58,1 \\
\hline Idade (anos) & $18-29$ & 9 & 2,6 \\
& $30-39$ & 111 & 32,6 \\
& $40-49$ & 156 & 45,8 \\
& $50-59$ & 52 & 15,2 \\
& $60-69$ & 12 & 3,5 \\
\hline Tempo de TARV & $\geq 70$ & 1 & 0,3 \\
\hline Tempo de diagnóstico de HIV *anos & $<24$ meses & 151 & 44,3 \\
& $\geq 24$ meses & 190 & 55,7 \\
\hline Tabagismo & mediana 10 anos (percentil $25-75$ de $6-12$ anos) \\
& sim & 91 & 26,7 \\
\hline Atividade física & não & 228 & 66,9 \\
& sem dados & 22 & 6,4 \\
\hline & sim & 129 & 37,8 \\
& não & 190 & 55,7 \\
& sem dados & 22 & 6,5 \\
\hline
\end{tabular}

Nota: TARV= terapia antirretroviral

$\mathrm{Na}$ tabela 1 encontram-se os dados clínicos e epidemiológicos. Do total de pacientes, $198(58,1 \%)$ eram do sexo feminino e $143(41,9 \%)$ do sexo masculino. A síndrome metabólica(40) estava associada em 137 indivíduos (40,2\%). 
Tabela 2 - Distribuição da população estudada de acordo com os dados laboratoriais (CD4, carga viral, colesterol total, HDL colesterol, LDL colesterol, triglicérides e glicemia) de abril de 2006 a março de 2008.

\begin{tabular}{|c|c|c|c|}
\hline Variável & Categoria & $\mathbf{N}$ & $\%$ \\
\hline \multirow[t]{3}{*}{ CD4 (céls/mm³) } & $\leq 200$ & 13 & 3,8 \\
\hline & $200-350$ & 51 & 15,0 \\
\hline & $\geq 350$ & 277 & 81,2 \\
\hline \multirow[t]{2}{*}{ CV (cópias) } & $<10.000$ & 322 & 94,4 \\
\hline & $\geq 10.000$ & 19 & 5,6 \\
\hline \multirow[t]{3}{*}{ Colesterol total (mg/dl) } & $\leq 200$ & 190 & 55,7 \\
\hline & $200-239$ & 83 & 24,4 \\
\hline & $\geq 240$ & 68 & 19,9 \\
\hline \multirow[t]{2}{*}{$\mathrm{HDL}^{*}(\mathrm{mg} / \mathrm{dl})$} & $<40 /<50$ & 190 & 55,7 \\
\hline & $\geq 40 / \geq 50$ & 151 & 44,3 \\
\hline \multirow[t]{3}{*}{ LDL(mg/dl) } & $<130$ & 224 & 65,7 \\
\hline & $130-160$ & 53 & 15,5 \\
\hline & $\geq 160$ & 64 & 18,8 \\
\hline \multirow{2}{*}{$\begin{array}{l}\text { Triglicérides } \\
\text { (mg/dl) }\end{array}$} & $\leq 150$ & 124 & 36,4 \\
\hline & $>150$ & 217 & 63,6 \\
\hline \multirow[t]{3}{*}{ Glicemia (mg/dl) } & $<100$ & 233 & 68,3 \\
\hline & $100-126$ & 82 & 24,1 \\
\hline & $\geq 126$ & 26 & 7,6 \\
\hline
\end{tabular}

Nota: $\mathrm{CV}=$ carga viral, $\mathrm{HDL}=\mathrm{HDL}$ colesterol, $\mathrm{LDL}=\mathrm{LDL}$ colesterol, ${ }^{\text {de }}$ acordo com sexo

$\mathrm{Na}$ tabela 2 encontramos os dados referentes aos exames laboratoriais analisados. O perfil metabólico foi avaliado através dos dados de colesterol total, HDL-c, LDL-c e triglicerídeos. 
Gráfico 1 Distribuição dos esquemas antirretrovirais de acordo com os esquemas mais prevalentes em indivíduos atendidos no programa de lipodistrofia do Hospital Heliópolis-SP para correções cirúrgicas, abril de 2006 a março de 2008.

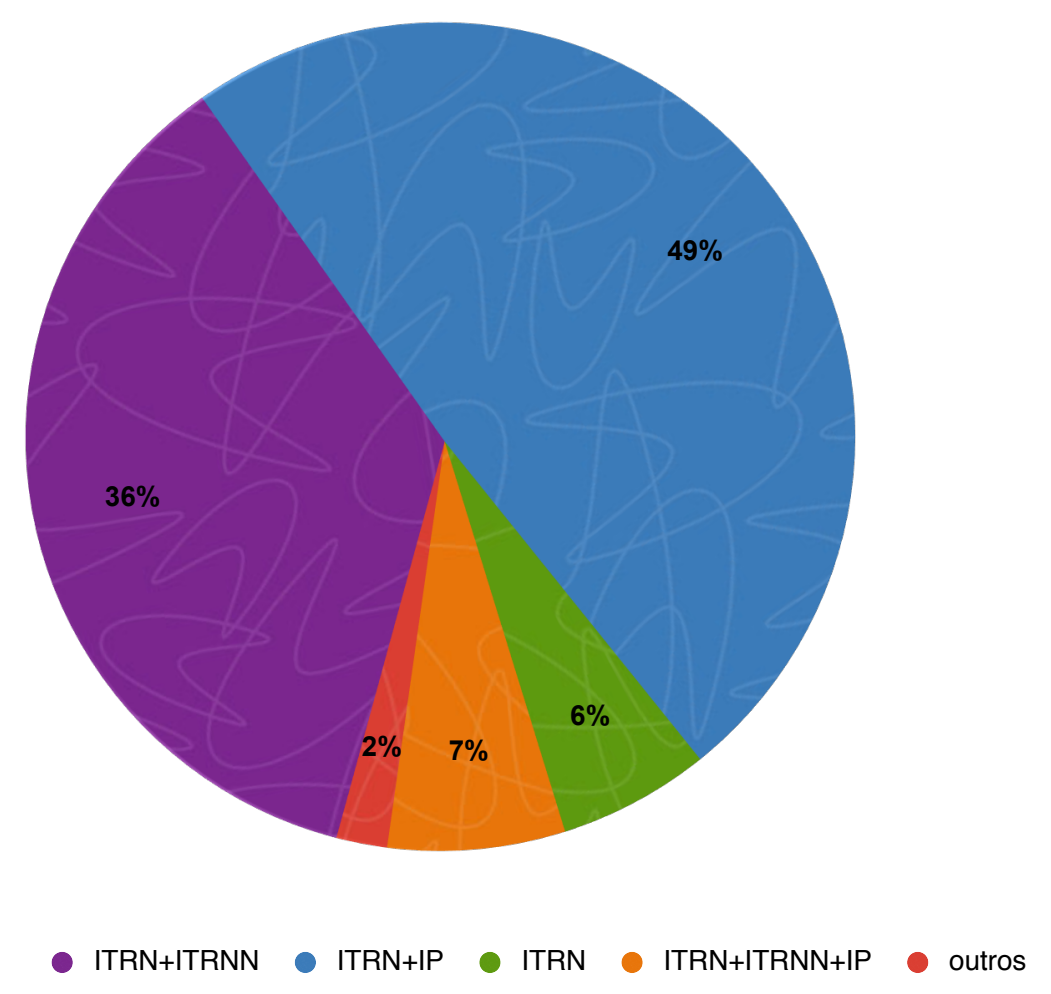

Os esquemas ARVs foram divididos em 5 grupos conforme gráfico 1 de acordo com as classes de ARVs. 
Tabela 3 - Avaliação antropométrica dos indivíduos estudados de acordo com os indicadores da distribuição de gordura corporal e indicadores de aumento de risco cardiovascular, abril 2006 a março de 2008

\begin{tabular}{cccc}
\hline Variável & Categoria & $\mathbf{N}$ & $\%$ \\
CB & desnutrição & 56 & 16,4 \\
& eutrofia & 257 & 75,4 \\
& obesidade & 28 & 8,2 \\
CMB & desnutrição & 25 & 7,4 \\
& eutrofia & 227 & 67,6 \\
IMC & obesidade & 84 & 25,0 \\
& desnutrição & 22 & 6,5 \\
& eutrofia & 191 & 56,0 \\
CC & excesso de peso & 128 & 37,5 \\
& sem RCV & 132 & 38,7 \\
GC & com RCV & 209 & 14,1 \\
& sem RCV & 36 & 85,9 \\
\hline & com RCV & 305 & 10,6 \\
\hline
\end{tabular}

Nota: $\mathrm{CB}=$ circunferência do braço, $\mathrm{CMB}=$ circunferência muscular do braço, IMC= índice de massa corporal, $\mathrm{CC}=$ circunferência da cintura, $\mathrm{RCQ}=$ relação cintura-quadril, $\mathrm{GC}=$ gordura corporal

Os resultados da avaliação antropométrica estão na tabela 3. 
Gráfico 2 - Padrão fenotípico dos indivíduos HIVIAids e lipodistrofia atendidos no programa de lipodistrofia do Hospital Heliópolis-SP para correções cirúrgicas, abril de 2006 a março de 2008.

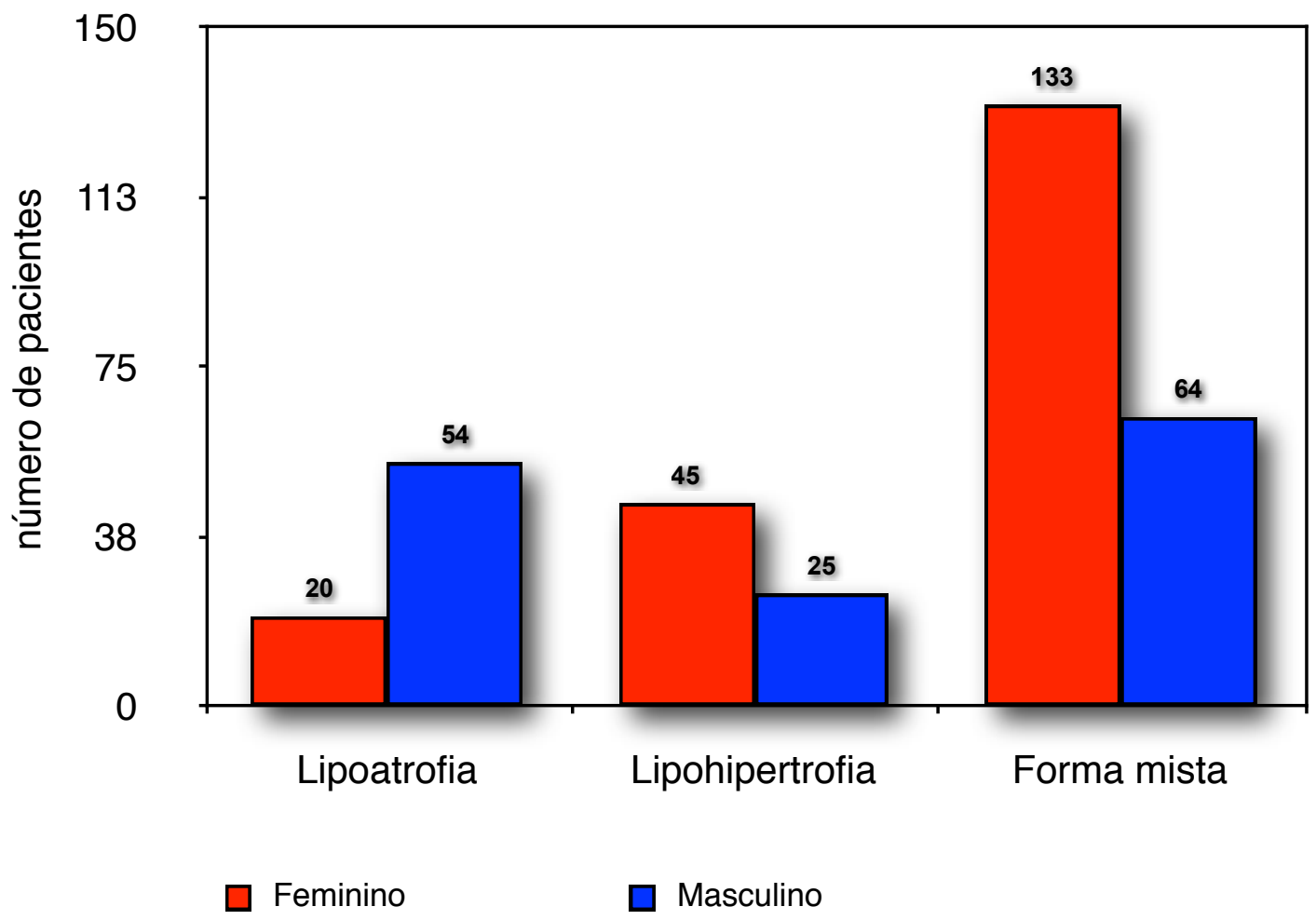

O padrão fenotípico da lipodistrofia associada ao HIV encontra-se no gráfico 2 onde observamos uma predominância da forma mista em 197 pacientes $(57,78 \%)$ seguida da forma lipoatrófica em 74 pacientes $(21,70 \%)$ e da forma lipohipertrófica em 70 pacientes $(20,52 \%)$. 
Gráfico 3 - Distribuição da lipoatrofia de acordo com a região anatômica e sexo em indivíduos atendidos no programa de lipodistrofia do Hospital Heliópolis-SP para correções cirúrgicas, abril de 2006 a março de 2008

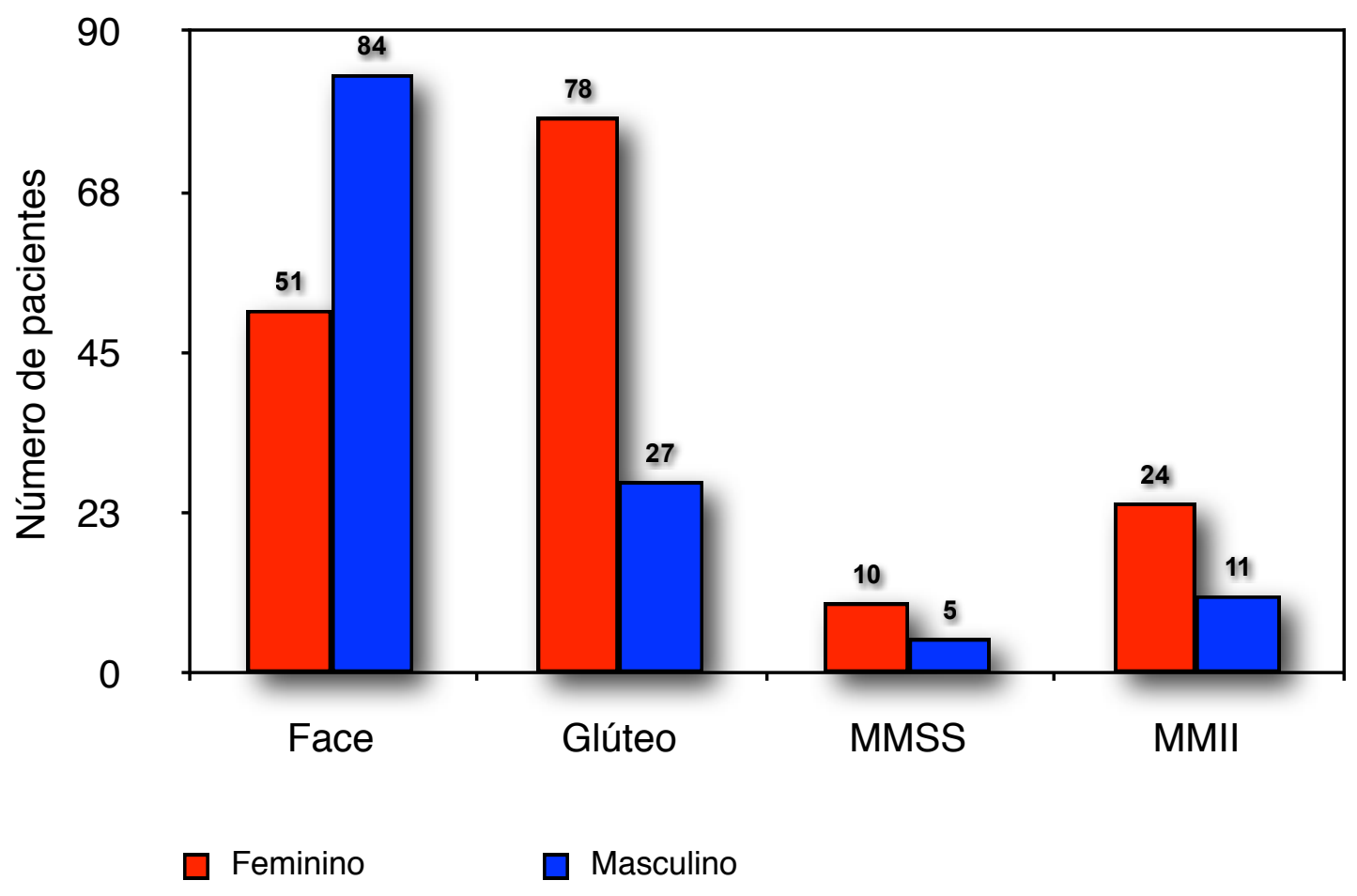

Nota: MMSS $=$ membros superiores, $\mathrm{MMII}=$ membros inferiores

A distribuição anatômica pode ser observada no gráfico 3 para lipoatrofia e gráfico 4 para lipohipertrofia. Observa-se um predomínio de lipoatrofia facial nos homens $(62,22 \%)$ e um predomínio de lipoatrofia glútea no sexo feminino $(74,29 \%)$. 
Gráfico 4 - Distribuição da lipohipertrofia de acordo com a região anatômica e sexo em indivíduos atendidos no programa de lipodistrofia do Hospital Heliópolis-SP para correções cirúrgicas, abril de 2006 a março de 2008

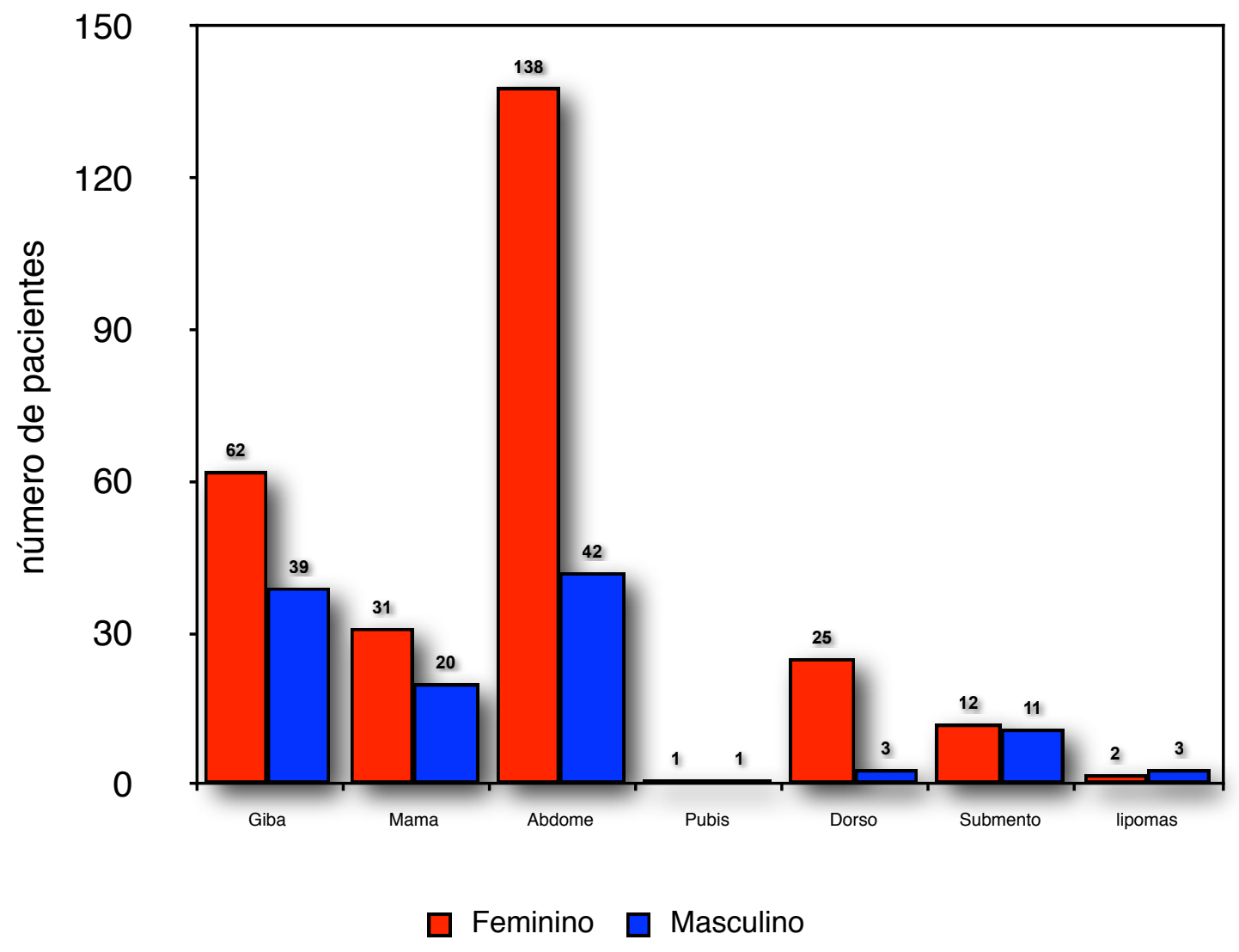


Tabela 4 - Associação entre síndrome metabólica e os fenótipos da lipodistrofia em indivíduos portadores de lipodistrofia/HIV atendidos no programa de lipodistrofia do Hospital Heliópolis no período de abril de 2006 à março de 2008.

\begin{tabular}{|c|c|c|c|c|c|}
\hline & \multicolumn{5}{|c|}{ Síndrome Metabólica } \\
\hline & \multicolumn{2}{|c|}{ Sim } & \multicolumn{2}{|c|}{ Não } & \multirow[b]{2}{*}{$p$} \\
\hline & $\mathrm{n}$ & $\%$ & $\mathrm{n}$ & $\%$ & \\
\hline Lipoatrofia & 7 & 9,5 & 67 & 90,5 & $<0,001$ \\
\hline Lipohipertrofia & 39 & 55,7 & 31 & 44,3 & 0,003 \\
\hline Forma mista & 91 & 46,2 & 106 & 53,8 & 0,008 \\
\hline
\end{tabular}

Foram realizados testes de associação entre os fenótipos da lipodistrofia e síndrome metabólica. Houve uma associação de lipohipertrofia e síndrome metabólica, como pode ser observada na tabela 4.

$\mathrm{Na}$ análise, estratificada por região anatômica, foi observada uma associação da síndrome metabólica com a lipodistrofia para as regiões abdominal e dorso-cervical (giba) $(p<0,001)$. 
Tabela 5 - Associação de lipodistrofia e indicadores antropométricos com forte relação com o aumento de risco cardiovascular em pacientes HIV/Aids atendidos no programa de lipodistrofia do Hospital Heliópolis-SP para correções cirúrgicas da lipodistrofia de abril 2006 a março de 2008.

\begin{tabular}{llllllllll}
\hline & \multicolumn{3}{c}{ Relação cintura-quadril } & \multicolumn{4}{c}{ Circunferência da cintura } \\
\hline & $\mathrm{n}$ & $\mathrm{RCV}(\%)$ & $\tilde{n} \mathrm{RCV}(\%)$ & $p$ & $\mathrm{n}$ & $\mathrm{RCV}(\%)$ & $\tilde{\mathrm{n}} \mathrm{RCV}(\%)$ & $p$ \\
Lipoatrofia & 55 & 74,3 & 25,7 & $<0,001$ & 112 & 16,2 & 83,8 & $<0,001$ \\
Lipohipertrofia & 63 & 90,0 & 10,0 & 0,865 & 57 & 81,4 & 18,6 & $<0,001$ \\
Forma Mista & 187 & 94,9 & 5,1 & $<0,001$ & 140 & 71,1 & 28,9 & $<0,001$ \\
\hline Nota: RCV= risco cardiovascular, ñ RCV= não risco cardiovascular & & &
\end{tabular}

Na tabela 5 observamos a associação das formas da lipodistrofia com as variáveis antropométricas relacionadas com risco cardiovascular, com destaque para a associação da lipohipertrofia e da forma mista com risco cardiovascular aumentado. 


\section{Discussão}

Neste estudo apresentamos as principais características clínicas e laboratoriais encontradas nos pacientes HIVIAIDS com lipodistrofia, ou seja, as alterações do contorno corporal decorrentes da redistribuição de gordura. Uma característica desta população estudada é o fato de todos os pacientes já apresentarem as alterações corporais descritas, pois foram selecionados dentro de um universo do programa de correção cirúrgica para lipodistrofia do Hospital Heliópolis. Sendo assim, podemos dizer que seria esperado que

estas alterações fossem bastante evidentes a ponto de os levarem a procurar uma maneira de corrigi-las. Isso indica que o grupo estudado caracteriza-se por apresentar alterações significativas, acima dos valores médios da população em geral acometida pela infecção pelo HIV.

Neste estudo $58,1 \%$ dos pacientes eram do sexo feminino e $41,9 \%$ do sexo masculino demonstrando uma preocupação com a aparência corporal em ambos os sexos, já que essa foi a motivação da busca do atendimento no ambulatório de lipodistrofia do Hospital Heliópolis. No trabalho de Santos e colaboradores (33) houve uma maior percepção da alteração do contorno corporal em pacientes do sexo masculino $(68,4 \%)$. Também no sexo masculino foi detectada maior alteração corporal nos dados de Diehl e colaboradores ${ }^{(31)}$. Em ambos estudos havia uma prevalência maior do sexo masculino na população estudada, dada as condições de recrutamento dos pacientes. Disso podemos inferir que existe uma preocupação equivalente com a aparência, ainda que não se possa buscar uma proporcionalidade em 
relação à população que apresenta alterações corporais, já que esta é de difícil definição e classificação até o momento $(29,30)$.

A faixa etária onde se observou uma maior freqüência de alterações foi de $40-49$ anos $(45,8 \%)$ e com o uso de antirretrovirais superior à 24 meses $(55,7 \%)$, ou seja, um tempo prolongado de exposição aos ARVs. Estes dados estão de acordo com a literatura segundo Grunfeld ${ }^{(20)}$ em que o tempo médio de aparecimento da lipodistrofia foi de 18 à 24 meses e também com os dados de Diehl (31) onde a média de idade nos pacientes com lipodistrofia foi de 44,19 anos e a duração média da TARV foi de 85,4 meses. O tempo médio de diagnóstico do HIV foi de 10 anos nos pacientes ora estudados. Todos estes dados demostram que a lipodistrofia mais acentuada, em sua maioria, não aparece precocemente. Contudo, não podemos afirmar que a lipodistrofia, em qualquer grau de intensidade de suas manifestações, é de aparecimento tardio, pois este estudo não realizou a busca de alterações em pacientes em fases iniciais da doença e do tratamento.

Nos dados referentes aos hábitos de vida, encontramos $26,7 \%$ de fumantes e $55,7 \%$ de não praticantes de atividade física regular. Estes dados podem indicar que não existe uma preocupação maior com práticas que possam melhorar as condições clínicas destes pacientes, inclusive das alterações do contorno corporal. O aumento da atividade física, principalmente da atividade aeróbica promove melhoras nas alterações metabólicas (dislipidemia e resistência a insulina), bem como a redução de gordura visceral abdominal(67). 
$\mathrm{Na}$ análise dos dados laboratoriais encontramos uma população com controles imunológicos e virológicos adequados para os procedimentos cirúrgicos propostos, com 81,2 \% dos pacientes com contagem de células CD4 $\geq 350$ céls $/ \mathrm{mm}^{3}$ e 94,4\% com carga viral < 10.000 cópias. Porém, vale ressaltar que estes dois dados faziam parte dos critérios de inclusão para o programa de correções cirúrgicas, que determinava níveis de CD4 superior a 200 céls $/ \mathrm{mm}^{3}$ e carga viral inferior 10.000 cópias.

Um dos objetivos do estudo foi avaliar o perfil metabólico desses pacientes. Observamos que $19,9 \%$ dos pacientes apresentavam níveis de colesterol total superior à $240 \mathrm{mg} / \mathrm{dl}$, triglicérides superior à $150 \mathrm{mg} / \mathrm{dl} \mathrm{em}$ $63,6 \%$, HDL colesterol inferior aos valores considerados adequados para o sexo em $55,7 \%$ dos casos e glicemia superior a $100 \mathrm{mg} / \mathrm{dl} 31,7 \%$. Esses dados não consideram a possibilidade desses pacientes estarem submetidos a tratamento específicos destas alterações, o que poderia elevar a gravidade do quadro apresentado.

Outro objetivo era avaliar a presença da síndrome metabólica(40) nos pacientes com lipodistrofia. A prevalência da SM em indivíduos HIV tem sido estimada variando de $7-45 \%$ de acordo com o desenho do estudo e parâmetros avaliados(45), porém sua associação à lipodistrofia ainda não está configurada. No Brasil, há muito poucos dados sobre a prevalência de SM. Oliveira e cols. estimaram que $30 \%$ dos adultos em uma área rural do nordeste brasileiro (não infectados pelo HIV, idade média de 49 anos) fossem portadores de SM, pelos critérios do NCEP-ATPIII(68). Nesta população encontramos uma taxa elevada de síndrome metabólica (40,2\%). 
No estudo de Diehl e colaboradores a freqüência de síndrome metabólica foi de $36 \%$ nos pacientes com lipodistrofia(31). Estes dois dados são preocupantes, pois acrescentam, às manifestações e tratamento das alterações do contorno corporal, o risco de doenças cardiovasculares presentes na SM. O risco das alterações cardiovasculares associadas a SM, na população em geral, tem sido exaustivamente demonstrado por estudos prospectivos ${ }^{(69)}$. Embora haja evidências de que os pacientes HIV apresentem maior risco de infarto do miocárdio do que a população geral, não se definiu ainda a associação de SM com risco cardiovascular nestes pacientes ${ }^{(69)}$.

Os principais esquemas antirretrovirais em uso no momento da avaliação no serviço de lipodistrofia do Hospital Heliópolis continham a associação de ITRN e IP, fato que poderia colaborar com a elevada incidência da síndrome metabólica entre esses pacientes. Sabe-se que os IPs estão relacionados ao aumento de colesterol e triglicérides e também ao acúmulo de gordura visceral abdominal ${ }^{(70,71)}$. Não encontramos associação significativa dos esquemas ARVs com as alterações corporais, provavelmente pela heterogeneidade de esquemas utilizados previamente, o que torna difícil a aferição dessa associação.

Considerando que a análise do estado nutricional deve compor a avaliação global do paciente com HIVIAIDS e que a dieta inadequada pode colaborar para comprometer ainda mais este paciente em uso de TARV, os estudos que avaliam perfil lipídico de pessoas vivendo com HIVIAIDS recomendam a realização das medidas antropométricas para determinar a 
composição corporal. Seguindo os critérios antropométricos utilizados neste estudo, observamos que a maioria dos pacientes era eutrófica $(56 \%)$, segundo o IMC ${ }^{(60,61)}$. Não foram encontrados dados para populações com lipodistrofia e HIV, porém, dados de um estudo brasileiro de Jaime e colaboradores ${ }^{(72)}$ mostram que $65,9 \%$ de um total de 223 pacientes em uso de TARV eram eutróficos.

Outras medidas utilizadas para avaliar o estado nutricional foram a circunferência do braço e a circunferência muscular do braço; verifica-se um predomínio de eutrofia nestes pacientes, com $75,4 \%$ na primeira circunferência e $67,6 \%$ na segunda. Porém, foi observada um elevada taxa de pacientes com excesso de peso, segundo o IMC $(37,5 \%)$.

Quanto à desnutrição, foram encontrados $6,5 \%$ de pacientes de acordo com o IMC. Esse dado se aproxima dos dados de Jaime e colaboradores ${ }^{(72)}$ em população HIV em uso de TARV que registra $3,6 \%$ de desnutrição segundo o mesmo critério. Ao avaliarmos a desnutrição, levando em conta a circunferência do braço, encontramos uma taxa ainda mais elevada (16,4\%). Isso se deve ao fato de a lipodistrofia alterar a distribuição de gordura na região dos membros superiores, o que torna esse critério mais propenso à deteç̧ão da desnutrição. Deve-se considerar no entanto, que a CB é o parâmetro nutricional antropométrico recomendado pela OMS para a estimativa da proteína muscular esquelética total ${ }^{(60)}$.

As reservas de tecido adiposo corporal e, conseqüentemente, as reservas de calorias, são estimadas pelas medidas da espessura das dobras cutâneas que servem para calcular a porcentagem de gordura corporal 
conforme descrito na metodologia. Atualmente esse é um dos métodos mais simples, fáceis e precisos para avaliar a composição corporal, correlacionando-se satisfatoriamente com outros métodos mais complexos (pesagem hidrostática, bioimpedância e densitometria) ${ }^{(73,74)}$. Neste estudo, $85,9 \%$ dos pacientes apresentaram excesso de gordura. Essa taxa, bastante elevada, não pode ser comparada, pois não existem na literatura estudos similares. É possível que estes valores elevados estejam relacionados com o tempo prolongado de doença presente nestes pacientes, demonstrando uma gravidade maior da lipodistrofia com o passar do tempo.

As medidas da circunferência da cintura permitem identificar portadores de obesidade androgênica, fato associado a um maior risco de doença arterial crônica ${ }^{(42,75)}$, assim como a relação cintura/quadril, que atualmente é o indicador mais utilizado para identificar esse tipo de risco relacionado à distribuição de gordura. Neste estudo, as alterações significativas da CC alcançam $61,3 \%$ dos pacientes; e na RCQ , $89,4 \%$. Esses dados bastante expressivos servem de alertas para os riscos associados às doenças cardiovasculares nessa população. No estudo de Diehl (31) e colaboradores, que considera uma população de pacientes portadores de HIV em uso de TARV, foram encontrados $17 \%$ de alterações da CC, discrepância que corrobora a gravidade das taxas encontradas neste estudo.

Em relação ao padrão fenotípico da lipodistrofia, encontramos um predomínio da forma mista $(57,8 \%)$, seguido da lipoatrofia $(21,7 \%)$ e da lipohipertrofia $(20,5 \%)$. Na estratificação por gênero, observamos um 
predomínio do sexo feminino na forma mista $(67,5 \%)$ e na forma lipohipertrófica $(64,3 \%)$, enquanto que no sexo masculino foi mais prevalente a lipoatrofia (73\%). Estes dados vão ao encontro com os achados de Diehl e colaboradores (31), que relatam, através das entrevistas realizadas, um predomínio da lipohipertrofia (43\%) e da forma mista (40\%) no sexo feminino, e lipoatrofia (34\%) no sexo masculino. Apesar da falta de estudos dirigidos para a análise da percepção corporal alterada, observa-se que as mulheres estão um pouco mais atentas a possíveis mudanças corporais, fenômeno possivelmente relacionado à maior cobrança por perfeição física imposta pela sociedade. Fato que pode ser reforçado com o estudo de Santos e colaboradores (33), no qual foi observado que $32 \%$ dos homens contra $15 \%$ das mulheres com alterações da redistribuição de gordura corporal evidente ao exame clínico deixaram de relatar tais alterações durante a entrevista. Lichtenstein e colaboradores também reforçam os dados mais significativos de lipoatrofia no sexo masculino e lipohipertrofia no feminino $(18,19)$.

Na estratificação da lipoatrofia por região anatômica, observou-se uma prevalência da lipoatrofia facial nos homens $(62,2 \%)$ e da lipoatrofia glútea nas mulheres (74,3\%). Enquanto que na lipohipertrofia, as alterações abdominais foram predominantes em ambos os sexos, porém, com uma incidência maior no sexo feminino (40,5\% feminino, 12,5\% masculino). Esta distribuição, diretamente relacionada às queixas dos pacientes e à motivação para a procura do programa de correções cirúrgicas, pode estar relacionada às características culturais brasileiras e às pressões sociais que 
incidem no imaginário do corpo da mulher. Para o homem, diferentemente, as pressões sobre a imagem incidem prioritariamente na sua exposição social, ou seja, na face exposta.

A associação da lipodistrofia e a Síndrome Metabólica sempre foi uma questão polêmica. Nos relatos iniciais dos casos de lipodistrofia, esta associação era sempre mencionada pelos estudiosos como sendo parte da síndrome da lipodistrofia (alterações corporais + distúrbios metabólicos)(4,5,9). Neste estudo realizamos os testes de associação da SM aos fenótipos da lipodistrofia e pudemos observar que houve uma associação direta da SM com a lipohipertrofia em 55,7\% (p 0,003) e uma não associação com lipoatrofia em $90,5 \%(p<0,001)$. Isto vai ao encontro da preocupação com os riscos das doenças cardiovasculares acarretados pela lipodistrofia, ou seja, do ponto de vista metabólico, para além das questões relativas aos problemas decorrentes da aparência corporal social.

A importância da avaliação da síndrome metabólica neste estudo esta diretamente relacionada ao padrão da lipohipertrofia encontrado. O acúmulo de gordura abdominal já é conhecido como fator de risco para DCV, fazendo parte de um dos critérios do NCEP para definir $S M^{(40)}$. Sabendo-se que, neste estudo ora apresentado, a lipohipertrofia abdominal foi mais prevalente em ambos os sexos e que a medida da circunferência da cintura faz parte de um dos critérios que compõem a definição da síndrome metabólica, fica evidenciado a necessidade da mensuração da circunferência da cintura na prática clínica como um indicador de risco para doença cardiovascular. 
Apesar deste estudo ser de análise retrospectiva, com coleta de dados de prontuários, sem padronização da coleta dos dados laboratoriais, os resultados aqui encontrados apontam para a necessidade de um diagnóstico precoce desta alterações corporais e laboratoriais referentes aos distúrbios metabólicos, bem como a instituição de medidas preventivas e terapêuticas que melhorem a qualidade de vida e a sobrevida desses indivíduos. Procedimentos simples na prática cotidiana ambulatorial podem avaliar e controlar os fatores de risco durante o atendimento regular ao paciente HIVIAIDS. 


\section{Conclusões}

1. As características gerais da população estudada evidenciam uma distribuição maior da lipodistrofia no sexo feminino, na população com mais de 10 anos de diagnóstico da infecção pelo HIV, em uso de TARV por mais de 24 meses e na faixa etária de 40-49 anos.

2. O padrão fenotípico da lipodistrofia mais encontrado na população estudada foi a forma mista $(57,8 \%)$, seguido da lipoatrofia $(21,7 \%)$ e lipohipertrofia (20,5\%). A forma mista foi a queixa principal das mulheres, enquanto a lipoatrofia, a dos homens. As regiões mais acometidas, referentes a lipoatrofia, foram a face nos homens e os glúteos nas mulheres, enquanto que o abdome foi o mais acometido na forma lipohipertrófica em ambos os sexos.

3. A análise do perfil metabólico evidencia porcentagens relevantes de hipertrigliceridemia, de redução dos níveis de HDL-colesterol e de elevação dos níveis glicêmicos.

4. A síndrome metabólica foi encontrada em $40,2 \%$ dos pacientes e esteve diretamente relacionada com a lipohipertrofia, principalmente nos casos de lipohipertrofia abdominal.

5. O risco aumentado para doenças cardiovasculares, de acordo com os indicadores de distribuição de gordura corporal avaliados, foi observado em $85,9 \%$ dos pacientes.

6. O estudo demonstrou uma relação da lipodistrofia com os indicadores antropométricos com forte associação com o aumento de risco 
cardiovascular (circunferência da cintura e relação cintura-quadril) principalmente na forma lipohipertrófica.

7. Apesar dos dados antropométricos não constituírem metodologia usual para avaliação do risco cardiovascular, sua utilização no acompanhamento de pacientes HIVIAIDS pode ser de grande auxílio na prevenção dos riscos que envolvem essa população. 


\section{Referências Bibliográficas}

1.Power R., Tate H.L., McGill S.M., Taylor C. A qualitative study of the psychosocial implications of lipodystrophy syndrome on HIV positive individuals. Sex Transm Infect 2003;79:137-41.

2.Aids Epidemic Update, Novembro 2010. Disponível em: http:// www.unaids.org/globalreport/Global_report.htm.

3.Boletim Epidemiológico de Aids/DST 2006, disponível em www.aids.gov.br

4.Wierzbicki AS, Purdon SD, Hardman TC, Kulasegaram R, Peters BS. HIV lipodystrophy and its metabolic consequences: implications for clinical practice. Curr Med Res Opin. 2008 Mar;24:609-24.

5.Carr A, Samaras K, Burton S, et al. A Syndrome of peripheral lipodystrophy, hyperlipidaemia and insulin resistance in patients receiving HIV protease inhibitors. AIDS 1998;12:51-8.

6.Viraben R, Aquilina C. Indinavir-associated lipodystrophy. AIDS 1998; 12 : F37-39.

7.Miller KD, Jones E, Yanovski JA, Shankar R, Feuerstein I, Falloon J. Visceral abdominal-fat accumulation with use of indinavir. Lancet 1998; 351 : $871-75$. 
8.Hengel RL, Watts NB, Lennox JL. Benign symmetric lipomatosis associated with protease inhibitors. Lancet 1997; 350: 1596.

9.Valente AMM, Reis AF, Machado DM, Succi RCM, Chacra AR. Alterações Metabólicas da Síndrome Lipodistrófica do HIV. Arq Brás Endocrinol Metab 2005; 49: 871-79.

10.Leow MK, Addy CL, Mantzoros CS. Clinical review 159: Human immunodeficiency virus/highly active antiretroviral therapy-associated metabolic syndrome: clinical presentation, pathophysiology, and therapeutic strategies. J Clin Endocrinol Metab. 2003; 88:1961-76.

11.Baril JG, Junod P, Leblanc R, Dion H, Therrien R, Laplante F, Falutz J, Côté P, Hébert MN, Lalonde R, Lapointe N, Lévesque D, Pinault L, Rouleau D, Tremblay C, Trottier B, Trottier S, Tsoukas C, Weiss K. HIV-associated lipodystrophy syndrome: A review of clinical aspects. Can J Infect Dis Med Microbiol. 2005;16:233-43.

12.Power R, Tate HL, McGill SM, Taylor C. A qualitative study of the psychosocial implications of lipodystrophy syndrome on HIV positive individuals. Sex Trans Infect Dis 2003; 79: 137-41. 
13.Guaraldi G, Murri R, Orlando G. Lipodystrophy and quality of life og HIVinfected persons. AIDS Rev 2008; 10: 152-61.

14.Nachega JB, Trotta MP, Nelson M, Ammassari A. Impact of metabolic complications on antiretroviral treatment adherence: clinical and public health implications. Curr HIVIAIDS Rep. 2009; 6: 121-9.

15.Herranz P, de Lucas R, Pérez-España L, Mayor M. Lipodystrophy syndromes. Dermatol Clin. 2008; 26:569-78.

16.Calza I, Manfredi R, Chiodo F. Dyslipidemia associated with antiretroviral therapy in HIV-infected patients. J Antimicrob Chemother 2004; 53: 10-4.

17.Saint-Marc T, Partisani M, Poisot-Martin I et al.A syndrome of peripheral fat wasting (lipodystrophy) in patients receiving long-term nucleosides analogue therapy. AIDS 1999; 13: 1659-67.

18.Lichtenstein KA. Redefining lipodystrophy syndrome: risk and impact on clinical decision making. J Acquired Immune Defic Syndr 2005; 39:395-400.

19.Lichtenstein KA, Delaney KM, Armon C, Ward DJ, Moorman AC, Wood KC, et al; HIV Outpatient Study Investigators. Incidence of and risk factors for lipoatrophy (abnormal fat loss) in ambulatory HIV-1-infected patients. J Acquir Immune Defic Syndr. 2003;32:48-56. 
20.Grunfeld C. Understanding the complications of antiretroviral drugs. Clin Infect Dis. 2008; 47:575-6.

21.Podzanczer D, Ferrer E, Martinez E, et al. How Much Fat Loss Is Needed for Lipodystrophy to Become Clinically Evident? AIDS Res Hum Retroviruses $2009 ; 25: 563-7$.

22.Panse I, Vasseur E, Raffin-Sanson ML, Staroz F, Rouveix E, Saiag P. Lipodystrophy associated with protease inhibitors. $\mathrm{Br} \mathrm{J}$ Dermatol 2000; 142:496-500.

23.Carr A, Workman C, Smith DE et al. Mitochondrial Toxicity (MITOX) Study Group. Abacavir substitution for nucleoside analogs in patients with HIV lipoatrophy: a randomized trial. JAMA. 2002; 288:207-15.

24.Gallant JE. Staszewski S, Pozniak AL, et al. Efficacy and safety of tenofovir DF vs stavudine in combination therapy in antiretroviral-naïve patients: 3-year randomized trial. JAMA 2004; 292:191-201.

25.McDermott AY, Terrin N, Wanke C, Skinner S, Tchetgen E, Shevitz AH.CD4+ cell count, viral load, and highly active antiretroviral therapy use are independent predictors of body composition alterations in HIV-infected adults: a longitudinal study.Clin Infect Dis. 2005;41:1662-70. 
26.Duong M, Petit JM, Piroth L, Grappin M, Buisson M, Chavanet P, Hillon P, Portier $\mathrm{H}$. Association between insulin resistance and hepatitis $\mathrm{C}$ virus chronic infection in HIV-hepatitis C virus-coinfected patients undergoing antiretroviral therapy.J Acquir Immune Defic Syndr. 2001; 27:245-50.

27.Villaroya F, Domingo P, Giralt M. Drug-inducec lipotoxicity: lipodystrophy associated with HIV-1 infection and antirretroviral therapy. Biochim Biophys Acta, 2010; 1801:392-9.

28.Corless IB, Kirksey KM, Kemppainen J, Nicholas PK, McGibbon C, Davis SM, Dolan S. Lipodystrophy-associated symptoms and medication adherence in HIVIAIDS. AIDS Patient Care STDS. 2005;19:577-86.

29.Chen D, Misra A, Garg A. Lipodystrophy in Human Immunodeficiency Virus-Infected Patients. J Clin Endocrinol Metab 2002; 87: 4845-56.

30.Jacobson DL, Knox T, Spiegelman D et al. Prevalence of, evolution of, and risk factors for fat atrophy and fat deposition in a cohort of HIV-infected men and women. Clin Infect Dis 2005;40:1837-45.

31.Diehl LA, Dias JR, Paes AC, Thomazini MC, Garcia LR, Cinagawa E, Wiechmann SL, Carrilho AJ. Prevalence of HIV-associated lipodystrophy in 
Brazilian outpatients: relation with metabolic syndrome and cardiovascular risk factors. Arq Bras Endocrinol Metabol. 2008; 52:658-67.

32.Monnerat BZ, Cerutti Junior C, Caniçali SC, Motta TR. Clinical and biochemical evaluation of HIV-related lipodystrophy in an ambulatory population from the Hospital Universitário Cassiano Antonio de Morais, Vitória, ES, Brazil. Braz J Infect Dis. 2008 Aug;12:364-8.

33.Santos CP, Felipe YX, Braga PE, Ramos D, Lima RO, Segurado AC. Selfperception of body changes in persons living with HIVIAIDS: prevalence and associated factors. AIDS. 2005;19 Suppl 4:S14-21.

34.Caron-Debarle M, Lagathu C, Boccara F, Vigouroux C, Capeau J. HIVassociated lipodystrophy: from fat injury to premature aging. Trends Mol Med. 2010;16:218-29.

35.Johnson JA, Albu JB, Engelson ES, et al. Increased systemic and adipose tissue cytokines in patients with HIV-associated lipodystrohy. Am J Physiol Endocrinol Metab 2004; 286: E261-71.

36.Miro O, Lopez S, Cardellach F, Casademont J. Mitochondrial studies in HAART-related lipodystrophy: from experimental hypothesis to clinical findings. Antivir Ther 2005:10 (suppl 2): M73-81. 
37.Janneh O, Hoggard PG, Tjia JF, Jones SP, Khoo SH, Maher B, Back DJ, Pirmohamed M. Intracellular disposition and metabolic effects of zidovudine, stavudine and four protease inhibitors in cultured adipocytes. Antivir Ther. 2003;8:417-26.

38.Vigouroux C, Maachi M, Ngyen TH et al. Serum adipocytokines are related lipodistrophy and metabolic disorders in HIV-infected men under antiretroviral therapy. AIDS 2003; 17:1503-11.

39.Mallewa JE, Wilkins E, Vilar J, Mallewa M, Doran D, Back D, Pirmohamed M. HIV-associated lipodystrophy: a review of underlying mechanisms and therapeutic options. J Antimicrob Chemother. 2008;62:648-60.

40.Third Report of the National Cholesterol Education Program (NCEP). Expert Panel on Detection, Evaluation and Treatment of High Blood Cholesterol in Adults (Adult Treatment Panel III) final report. Circulation. 2002; 106: 3143-421.

41.Calza L, Manfred R, Chiodo F. Dyslipidaemia associated with antiretroviral therapy in HIV-infected patients. Journal of Antimicrobial Chemotherapy. 2004;53:10-14.

42.Grundy SM, Hansen B, Smith JrSC., Cleeman JI, Kahn RA and for Conference Participants, Clinical Management of Metabolic Syndrome: 
Report of the American Heart Association/National Heart, Lung, and Blood Institute/American Diabetes Association Conference on Scientific Issues Related to Management. Circulation. 2004; 109:551-6.

43.Gazzaruso C, Bruno C, Garzaniti A, Giordanetti S, Fratino P, Sacchi P et al. Hypertension among HIV patients: prevalence and relationships to insulin resistance and metabolic syndrome. J Hypertens. 2003; 21:1377-82.

44.Estrada V, Martinez-Larrad T, Gonzalez-Sanchez JL, de Villar NGP, Zabena C, Fernandez C, Serrano-Rios M. Lipodystrophy and metabolic syndrome in HIV infedted patients treated with antiretroviral therapy. Metabolism Clinical and Experimental. 2006; 55:940-5.

45.Worm SW, Lundgren JD. The metabolic syndrome in HIV. Best Pract Res Clin Endocrinol Metab. 2011; 25(3):487-99.

46.Behrens GM. Treatment options for lipodystrophy in HIV-positive patients. Expert Opin Pharmacother. 2008; 9:39-52.

47.Chen D, Misra A, Garg A. Lipodystrophy in Human Immunodeficiency Virus-Infected Patients. J Clin Endocrinol Metab 2002; 87: 4845-56.

48.Manual Clínico de Alimentação e Nutrição na Assistência a Adultos Infectados pelo HIV. Ministério da Saúde, Secretaria de Vigilância em Saúde, 
Programa Nacional de DST/AIDS. - 2006. (Série A. Normas e Manuais Técnicos) ISBN 85-334-1153-7.

49.World Health Organization - WHO. Obesity: preventing and managing the global epidemic. Report. Geneva; 2000.

50.Wierzbicki AS, Purdon SD, Hardman TC, Kulasegaram R, Peters BS. HIV lipodystrophy and its metabolic consequences: implications for clinical practice. Curr Med Res Opin. 2008;24:609-24.

51.Ascher B, Katz P. Facial lipoatrophy and the place of ultrasound. Dermatol Surg. 2006; 32:698-708.

52.Carr A. Treatment strategies for HIV lipodystrophy. Curr Opin HIV AIDS. $2007 ; 2: 332-8$.

53.Cofrancesco J Jr, Freedland E, McComsey G. Treatment options for HIVassociated central fat accumulation. AIDS Patient Care STDS. 2009; 23:5-18.

54.Wohl DA, Brown TT. Management of morphologic changes associated with antiretroviral use in HIV-infected patients. J Acquir Immune Defic Syndr. 2008; 49 Suppl 2:S93-S100. 
55.http://www.aids.gov.br/pagina/tratamento-de-lipodistrofia

56.Manual de tratamento da lipoatrofia facial: recomendações para o preenchimento facial com polimetilmetacrilato em portadores de HIV/Aids / Ministério da Saúde, Secretaria de Vigilância em Saúde, Departamento de DST, Aids e Hepatites Virais, 2009. (Série A. Normas e Manuais Técnicos) ISBN 978-85-334-1622-2.

57.Jelliffe, D.B. Evaluación del estado de nutrición de la comunidad; com especial referencia a las encuestas en las regiones en desarrollo. Genebra: Organización Mundial de la Salud. 291p. 1968.

58.Jelliffe DB, Jelliffe EF. Underappreciated pioneers. Quételet: man and index. Am J Clin Nutr. 1979;32: 2519-21.

59.World Health Organization. Obesity prevening and managing. The Global Epidemic. Report of a Who Consultation on Obesity. Geneva. WHO; 1995.

60.Lipschitz DA. Screening for nutritional status in the elderly. Prim Care. $1994 ; 21: 55-67$.

61.Durnin JVGA. \& Rahaman MM. The assessment of the amount of fat in the human body from thickness. Br. J. Nutr., 1967; 21: 681-9. 
62.Frisancho, AR. Anthropometric standards for the assessment of growth and nutritional status. The University of Michigan Press, 1990.

63.Durnin JVGA, Womersley J. Body fat assessed from total body density and its estimation from skinfold thickness: measurements on 481 men and women aged from 16 to 72 years. Br J Nutrition. 1974; 32: 77-97.

64.Lohman, T. G. Advances in body composition assessment. II. Champaign: Human Kinectics Publishers, 1992.

65.Ministério da Saúde. Secretaria de Vigilância em Saúde Programa Nacional de DST e Aids. Recomendações para terapia anti-retroviral em adultos e adolescentes infectados pelo HIV 2007/2008.

66.Nahas, MV. Atividade Física, Saúde e Qualidade de Vida: Conceitos e Sugestões para um Estilo de Vida Ativo. Londrina: Midiograf 2001. 238p.

67.Jones SP, Doran DA, Leat PB, Maher B, Pirmohamed M. Short-term exercise training improves body composition and hiperlipidaemia in HIVpositive individuals with lipodystrophy. AIDS. 2001; 15:2049-2051. 
68. Oliveira EP, Souza MLA, Lima MDA. Prevalência de síndrome metabólica em uma área rural do semiOárido baiano. Arq Bras Endocrinol Metab $2007 ; 51: 42-51$

69.Gami AS, Witt BJ, Howard DE, Erwin PJ, Gami LA, Somers VK, et al. Metabolic syndrome and risk of incident cardiovascular events and death - a systematic review and meta-analysis of longitudinal studies. J Am Coll Cardiol. 2007;49:403-14.

70.Holmberg SD, Moorman AC, Willianson JM, Tong TC, Ward DJ, Wood KC, Greenberg AE, Jansen RS and the HIV Outpatient Study (HOPS) Investigators. Protease inhibitors and cardiovascular outcomes in patients with HIV-1. Lancet.2002; 360, 1747-48.

71.Mary-Krause M, Cotte L, Simon A, Partisani M, Costagliola D. and the ClinicalEpidemiology Group from the French Hospital Database. Increased risk for myocardial infarction with duration of protease inhibitor therapy in HIV-infected men. AIDS; 2003, 17, 2479-86.

72.Jaime PC, Florindo AA, Latorre MRDO, Brasil BG, dos Santos ECM, Segurado AAC. Prevalência de sobrepeso e obesidade abdominal em indivíduos portadores de HIV/Aids, em uso de terapia anti-retroviral de alta potência. Rev Bras Epidemiol. 2004; 7(1): 65-72. 
73.Carvalho EB. Manual de Suporte Nutricional. São Paulo, Medsi, 1992.

74.TBW. Manual de Instruções do Compasso de Dobras Cutâneas. LANGE. São Paulo: TBW,1999.

75.Assis MA. Consulta de Nutrição. Santa Catarina: Insular, 1997. 


\section{Apêndices}

1. Ficha clínica para coleta dos dados

2. Carta de aprovação pelo Comitê de Ética em Pesquisa do Hospital Heliópolis

3. Carta de ciência da execução do Protocolo de Pesquisa pela Comissão de Ética para Análise de Projetos de Pesquisa do HCFMUSP e da FMUSP 
Apêndice 1. Ficha para coleta de dados

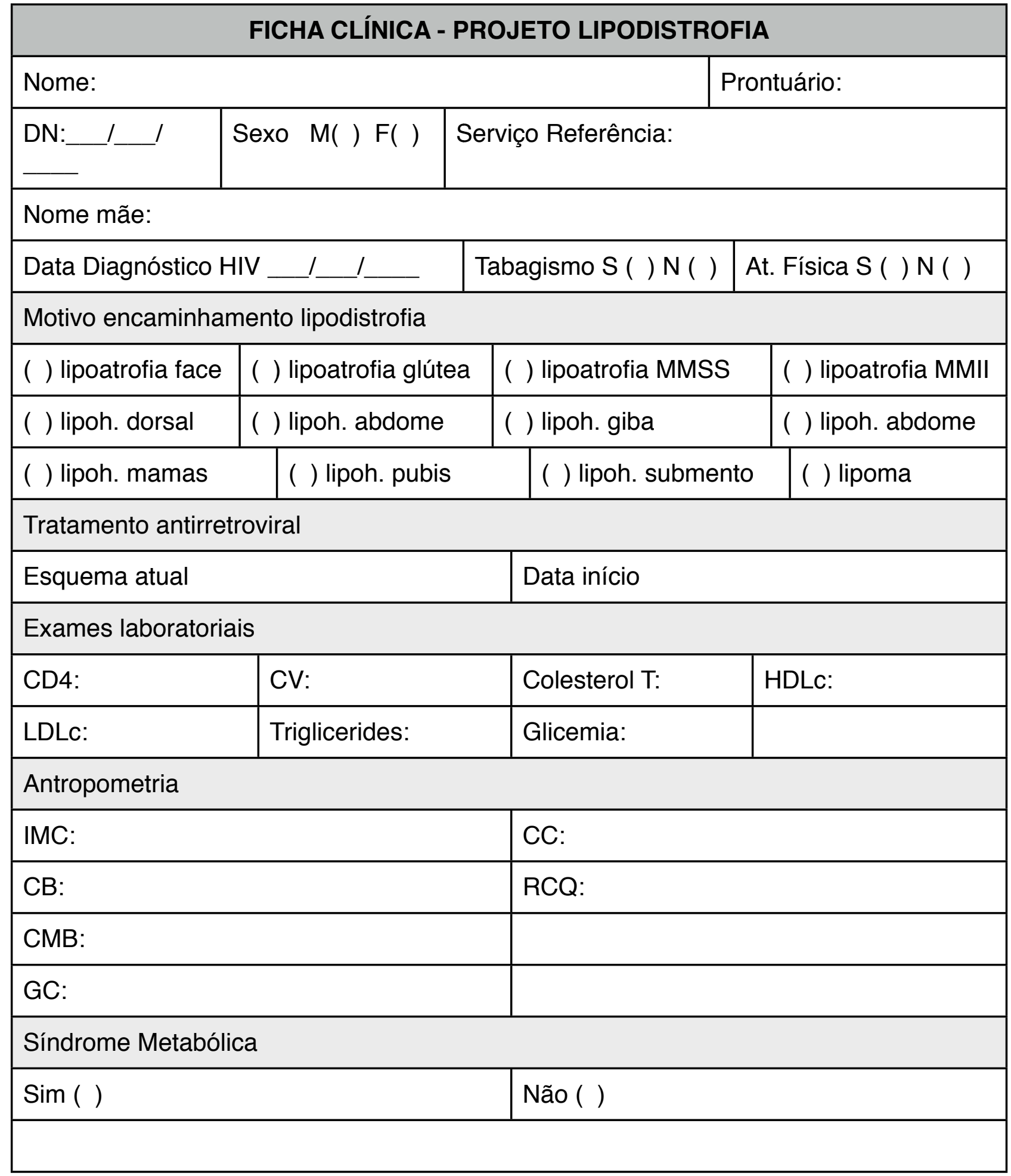

IMC= índice de massa corporal

$\mathrm{CB}=$ circunferência do braço

$\mathrm{CMB}=$ circunferência muscular do braço

$\mathrm{GC}=$ gordura corporal

$\mathrm{CC}=$ circunferência da cintura

$\mathrm{RCQ}=$ relação cintura-quadril 
São Paulo, 13 de novembro de 2007.

\section{APROVACÃO}

Ao Prezado

\section{Dr. Heverton Zambrini}

Vimos por meio desta informar que o projeto de pesquisa: "Avaliação dos fatores relacionados á lipodistrofia em pacientes com HIV/AIDS atendidos no Ambulatório de Lipodistrofia do Hospital Heliópolis", registrado neste CEP sob n 584, tendo como relator Dr. Juvêncio José Duailibe Furtado, foi aprovado por este Comitê de Ética em pesquisa em: $13 / 11 / 2007$.

Lembramos que é obrigatório o envio de relatório anual e final para este Comitê de Ética em Pesquisa.

Atenciosamente,

COMITE UL EIILA EM RESUUISA HOSPITAL HELIÓPOLIS JOZIAS DE ANDRADE SOBRINHO

Coordenador

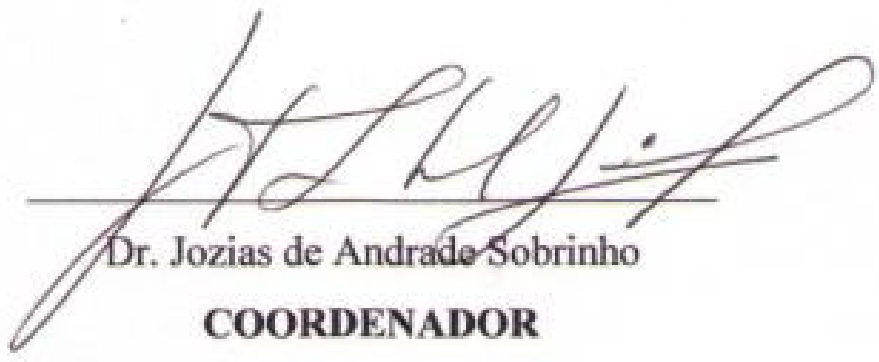

Rua Cônego Xavier, 276 - Sacomã - São Paulo - PS-Externa - CEP 04231-030. Fone: $6215-1001$ / 2274-7600 ramal 105 / Fax: 6162-6764

E-mail: cep_heliopolis@yahoo.com.br e Site www.hospitalheliopolis.org.br 
Ao

Departamento de Moléstias Infecciosas e Parasitárias

O Presidente da Comissão de Ética para Análise de Projetos de Pesquisa - CAPPesq da Diretoria Clínica do Hospital das Clínicas e da Faculdade de Medicina da Universidade de São Paulo, em 03.04.08, tomou ciência da execução do Protocolo de Pesquisa $n^{\circ}$ 0155/07, intitulado: "AVALIAÇĀO DOS FATORES RELACIONADOS A LIPODISTROFIA EM PACIENTES COM HIV/AIDS ATENDIDOS NO HOSPITAL HELIÓPOLIS".

No que tange à sua parte empírica está sendo desenvolvido na UGA I - UNIDADE DE GESTĀO ASSISTENCIAL - HOSPITAL HELIÓPOLIS, tendo seu Comitê de Ética aprovado o estudo em 13.11.07.

Pesquisador (a) Responsável: PROF. DR. ANTONIO CARLOS NICODEMO Pesquisador (a) Executante: DR. HEVERTON ZAMBRINI

CAPPesq, 03 de abril de 2008.

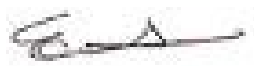

PROF. DR. EDUARDO MASSAD

Presidente

Comissão de Ética para Análise de Projetos de Pesquisa 